\title{
Formal Identification of Sentiment Effects in Asset Markets
}

\author{
Peter G. Dunne ${ }^{\dagger}$ \\ Central Bank of Ireland, Dame Street, Dublin 2, Ireland \\ John Forker \\ University of Bath, School of Management, Bath, UK \\ Ronan Powell \\ University of New South Wales, Sydney, Australia \\ Andrey Zholos \\ Queen's University Management School, Belfast, UK
}

19 April, 2012

\begin{abstract}
It is generally accepted that excessive exuberance or gloom in investor sentiment contributes to booms and crashes in asset prices but, because of its complex interaction with other aspects of the valuation process, these effects are not easy to identify with statistical confidence and this limits the scope for crafting an adequate and early policy response. To fill this gap, we develop an ex ante valuation approach that assigns different measures of sentiment to separate roles in the valuation equation. One measure of sentiment is assigned to capture risk aversion effects relevant to discounting, while a broader-based investor sentiment index is assigned to capture changes in the perceived prospects for long-term earnings growth. We show that the difference in 'implied' long-run earnings growth explained 'with' and 'without' sentiment can be turned into a sentiment indicator that can be assessed with statistical significance. Out-of-sample testing using the Dow 30 index shows that sentiment effects can often be confidently identified as widespread, significant and large. We find that the growth ratio is prescient as an early warning indicator of mis-valuations. Being able to draw attention to such statistically verifiable arbitrage opportunities in a timely fashion offers macro-prudential policy makers a more targeted policy response than making alterations to poorly focused policy instruments such as interest rates.
\end{abstract}

KEYWORDS: Bubbles; Fundamental Valuation; Sentiment; Early warning indicators. JEL Classification: E32, E44, E58, E66, G10, G12, G14.

\footnotetext{
† Corresponding author. Email: peter.dunne@centralbank.ie, Tel.: +44 07969066734.
} 


\section{INTRODUCTION}

Following the recent financial crisis there has been renewed interest in the debate as to whether monetary policy should be used to prick asset price bubbles. ${ }^{1}$ In advance of the recent crisis it is widely accepted that sentiment, facilitated by credit conditions, drove property prices in many advanced economies well beyond what was warranted based on average incomes. After the peak of the recent crisis fears abounded that bubbles were developing in commodities markets and in emerging economies as a direct result of the prolonged low interest rate and quantitative easing policies conducted in crisis-hit economies. So, while policy makers are often fearful of such occurrences they are seldom able to quantify their magnitude and this has implications for how confidently they can proceed in redressing the situation. At his confirmation hearing in the fall of 2009 the Chairman of the US Federal Reserve, Ben Bernanke described this as "the most difficult problem for monetary policy this decade."

The purpose of this paper is to improve the way the contribution of investor sentiment to the valuation of a representative equity market index is assessed, and thereby assist policy makers in alerting markets of the scope for arbitrage. Other authors have identified sentiment related mis-valuations and their effects on returns or at a micro level (Shiller, 2005; Kumar and Lee, 2006; Stambaugh, Yu and Yuan, 2012; Baker, Wurgler and Yuan, 2012 and Rhodes-Kropf, Robinson and Viswanathan, 2005) but identification of sentiment effects at a more aggregated level with adequate controls for systemic fluctuations in risk aversion and macroeconomic growth prospects remains allusive. Relatively little attention is devoted to measuring and documenting how significant the

\footnotetext{
${ }^{1}$ See "Fed Debates New Role: Bubble Fighter", by John Hilsenrath, Wall Street Journal, December 2, 2009, page
} A1. 
sentiment component is as a proportion of equity value. But the relative size of the sentiment effect is what matters from the perspective of a macro-prudential policy maker since larger and more pervasive sentiment effects pose greater contagion risks when they unwind.

Using ex ante estimates of valuation fundamentals, and building on an early indexbased study measuring departures of market from fundamental value (Lee, Myers and Swaminathan, 1999), our analysis produces an indicator of the contribution of investor sentiment to valuation that can be assessed with statistical confidence. Dealing with sentiment effects is challenging because there is more than one potential transmission mechanism by which sentiment can have an impact. We identify an assignment issue, and separate the risk aversion effects of sentiment from growth-related sentiment effects. This is operationalized in a very simple way by explicitly including an ex ante risk aversion indicator (the VIX index) in the discounting part of our valuation metric and by assigning sentiment effects (as measured by Baker and Wurgler, 2007) entirely to perceptions of long term earnings growth. The VIX index fluctuates with day-to-day changes in risk aversion (and the perceived amount of risk to which equities are exposed) while the Baker and Wurgler (BW) index of investor sentiment is a low frequency indicator based on the first principal factor of an array of broad-based sentiment variables that are very different from the VIX. This assignment allows us to construct a richly specified, non-linear model for valuation and it helps to identify periods in which conditions are conducive to pervasive mis-valuations arising from sentiment shocks.

We consider two aspects of the effects of sentiment. The first is based on a direct examination of the differences in the 'with' and 'without' sentiment valuations and this 
encompasses both the risk-aversion and growth-related effects of sentiment. The second viewpoint concentrates on the implied long-term growth rates of earnings derived from the valuation exercise 'with' and 'without' sentiment effects. The ratio of the squared differences in implied growth 'with' and 'without' sentiment produces a "sentiment-effects indicator" that is prescient and amenable to statistical testing. This can be formed into a test statistic that is Chi-Square distributed under the null hypothesis of no significant sentiment effects.

An out-of-sample test of our valuation metric also highlights the sensitivity of the valuation of the market index to sentiment effects when the required rate of return on equity and expected long-term growth rates are similar in magnitude. This is not a new finding, but it is more pronounced in our set-up because sentiment is sometimes more prominent in affecting perceived growth prospects rather than risk-aversion. It is our view that valuation metrics often used by policy makers do not properly addressed these nonlinearities and their interaction with sentiment effects. Thus, when ex ante systematic risk is low (or under-represents sentiment related risk) and expected long term growth is buoyant (also perhaps reflecting sentiment effects), then sentiment changes can begin to dominate the valuation process.

Our approach contributes to the extant literature that seeks to measure the role of earnings or dividend fundamentals, such as Campbell and Shiller (1988a and 1988b) or that explain returns rather than valuation levels as a function of sentiment, such as Baker and Wurgler (2007). These studies typically use a linearization of the valuation metric or avoid the step of capitalizing dividends or earnings and focus on excessive price-to-earnings or dividend ratios as evidence for exuberance and sentiment effects. There are some parallels 
between our analysis and that of Campbell and Diebold (2009) who argue that (p. 266) "time-varying expected business conditions likely capture time-varying risk whereas timevarying consumption/wealth may capture time varying risk aversion." The approach adopted in this paper focusses more specifically on three overlooked aspects of the impact of sentiment on security prices. First, we model important non-linear effects to improve the precision and richness of the estimated results. Second, we distinguish between the effects of sentiment through its effects on risk aversion as distinct from its effects on perceptions of growth. Finally, we aggregate the implied sentiment effects across stocks and assess their magnitude statistically.

In common with the above studies, we proceed to examine the returns relation as an error correction process. If returns can be regarded as reversing market inefficiencies on average, over time, then it is appropriate to improve the prediction of returns using our best estimates of such inefficiencies, and this is precisely what an error correction representation achieves (see, Engle and Granger, 1987). As far as is practically possible, we use an ex ante valuation approach. Given the forecasts of future earnings, three important unknowns remain in the valuation exercise. These include (i) risk premia associated with various risk factors, (ii) stock-specific sensitivities to such factors, and (iii) predictions of the long-run growth prospects for earnings. We use a single risk factor and we make use of option-implied measures of stock-specific betas to expose an ex ante market risk premium. The forward-looking betas from the analysis of Chang, Christoffersen, Jacobs and Vainberg (2012) are used as an input. ${ }^{2}$

\footnotetext{
2 This approach is supported by findings that stocks immune to sentiment are likely to possess option-implied betas that are a reliable reflection of ex-ante betas (Lemmon and $\mathrm{Ni}, 2008$ ). For more recent periods where the forward-looking betas are unavailable we use realized betas.
} 
We test for the relevance of the Fama-French and momentum factors in our analysis, but we do not find significant effects. ${ }^{3}$ The complexity introduced by multiple risk factors and the error associated with their exclusion does not appear to be as detrimental for valuation accuracy as omitting sentiment effects. ${ }^{4}$ Indeed, Buss, Schlag and Vilkov (2009) show that a simple CAPM can be defended when sentiment effects are either absent or controlled for. ${ }^{5}$ Recent studies by Kumar, Srescu, Boehme and Danielsen (2008) and Adrian and Franzoni (2009) demonstrate that once the estimation risk associated with beta and the risk premium are accounted for, the conditional CAPM has significant explanatory power in the cross-section of stock returns.

We estimate long-run earnings growth as an implicit non-linear function of investor sentiment and drivers of growth, including forecasts of long-term real GDP growth expectations. ${ }^{6}$ These expectations are obtained from the Survey of Professional Forecasters (SPF) compiled by the Philadelphia Federal Reserve. Firm-specific growth effects are accommodated by a moving average error process. Our reliance on longer term growth variables is essential to identifying the sentiment effect which is likely to be driven by investor over-reaction to short-term growth variables. The use of SPF variables also helps to counteract the distorting effects of optimistic analyst forecasts (Abarbanell and Lehavy,

\footnotetext{
3 There is little consensus on how many factors are needed to correctly price the risks associated with specific equity investments. Numerous asset pricing alternatives exist, such as the Arbitrage Pricing Theory model, the Fama-French (1993) three factor model, the models outlined in Haugen and Baker $(1996,2009)$ and Campbell and Vuoltenaho's (2004) Good-Beta/Bad-Beta model. With additional risk factors and unknown ex ante sensitivities to these factors valuation is impossible without a number of restrictions that can always be contested. At a very basic level, it is arguably the case that factors based on ex post portfolio returns are invalid in an ex ante context.

${ }^{4}$ Some of these issues are addressed by the 'behavioral finance' literature. For example, Benartzi and Thaler (1995) use the "narrow framing" argument to explain overestimates of the risk premium by investors. See also, Hirshleifer 2001, Brunnermeier 2001, Shiller 2005 and Epstein \& Schneider 2008.

5 Buss et al. (2009) find that there no role for firm characteristics such as size and book-to-market in a low sentiment regime. This finding is also supported by Chung \& Yeh (2009).

${ }^{6}$ Fong (2012) similarly uses expected real GDP growth rates when investigating risk-based explanations for the value premium.
} 
2003; Easton and Sommers, 2007; Ciciretti et al. 2009).7 Our approach therefore has a macroeconomic focus and in this respect, it has a correspondence with the asset price bubbles literature that uses macroeconomic fundamentals to identify market misalignments, such as Bordo and Jeanne (2002), Detken and Smets (2004), Machado and Sousa (2006), Alessi and Detken (2009), Agnello and Sckucknecht (2009), and Gerdesmeier, Reimers and Roffia (2009). Macroeconomic growth is generally slow moving (is related to expected future policy stances by monetary authorities) and used in combination with the near term I/B/E/S (hereafter IBES) forecasts of earnings reduces some of the excessive variation in asset-specific valuations associated with analysts' long term forecasts. ${ }^{8}$

Since the discounting process can introduce error we minimize this by using interest rate projections from the SPF in our discounting formulae. This overcomes a serious difficulty associated with the use of short term interest rates to represent the risk free rate in such models. Treasury Bill rates are often quite far from their expected long-run equilibrium and when they are used in capitalization formulae, such as the Gordon growth model, they can easily give rise to a negative denominator (i.e., a low risk free rate ' $r$ ' and a high growth rate ' $g$ ' will produce a negative or extremely small, $r$-g). We find that use of the long run forecast of the Treasury Bill yield from the SPF avoids this problem. More importantly, by including long term expected risk free rates we are accounting for the agents' expectations of future monetary policy decisions. Thus, we obtain plausible results for all of the Dow Jones 30 equities examined for all of the time periods in our sample. This

7While there may be incentives for analysts' to exaggerate equity-specific earnings growth it is difficult to think of reasons why macroeconomic growth forecasts would contain similar biases.

${ }^{8}$ Sharpe (2002) has shown that forecasts of longer term earning growth possess the largest part of the bias in analysts' forecasts. I/B/E/S stands for Institutional Brokers' Estimate System which is currently owned by Thomson Reuters. 
reliability characteristic is an attractive feature, rendering the method of practical benefit as an indicator of excessive sentiment effects.

Two important findings are worthy of mention. Firstly, we find that the valuation effects due to sentiment are quite pervasive across sectors of a very representative equity index. For the majority of firms in our sample it is difficult to reject the hypothesis that sentiment accounts for a significant proportion of value during some extended episodes. Secondly, we find that the growth-related sentiment effects are more prescient in identifying the presence of pervasive sentiment effects, and we suggest that this would be a better early warning indicator to inform macro-prudential policy. This suggests that subdued risk aversion changes can counteract the effects of growth-related sentiment effects and hide its presence. Our findings support the view that sentiment-related misvaluations can be statistically identified, and it therefore suggests that there is scope for arbitrage that could improve market efficiency. For example, policy makers could draw attention to such opportunities to mitigate their effects rather than changing policy variables in a way that could give rise to undesirable collateral damage.

The remainder of the paper is organized as follows. Section 2 outlines our valuation approach and our econometric methodology. Section 3 discusses data used in the application and Section 4 presents the main results with discussions about the likelihood of sentiment being a large contributor to valuations. Section 5 concludes. 


\section{AN OLD VALUATION METRIC WITH NEW CLOTHES}

To achieve, on average, a best fit for market prices given earnings and macroeconomic information we model fundamental value in the context of a modified Gordon Growth model that includes various ex ante inputs omitted in previous studies. The model is applied to earnings rather than dividends. ${ }^{9}$ We use consensus IBES 'core earnings' forecasts as the 'above-the-line' drivers of fundamental valuation and stock-specific sensitivity to forecasts of long-term economic growth from the SPF as 'below-the-line' drivers. While we use a baseline valuation derived with inputs that are familiar in the extant literature, we also extend the valuation metric to include other variables. The SPF provides long-run projections for real GDP growth and the risk free interest rate and, where possible, we use ex-ante option implied betas from Chang et al. (2012). Thus, our approach makes use of a number of ex ante variables that, to our knowledge, surpasses what is done in the extant literature.

We proceed to outline our fundamental valuation metric firstly without, and then including the effects of sentiment. We introduce sentiment effects firstly by including the VIX index as an ex ante proxy for the amount of systematic equity risk. We then assign growth related sentiment effects to the BW sentiment index in a growth equation. ${ }^{10}$ It is worthwhile noting that the VIX index and the BW investor index are not highly correlated.

\footnotetext{
${ }^{9}$ Fama and French (2001) describe how the proportion of firms in the US that make dividend payments fell from $66 \%$ in 1978 to only $20.8 \%$ in 1999 . This makes fundamental analysis based on dividends impractical for a large proportion of the market. There is a large literature on dividend irrelevance begun by Modigliani \& Miller (1961) and extended by Miller and Rock (1985) relating the dividend decision to one of signalling an absence of 'over-investment'. Our view is that uncertainty as to whether earnings are optimally distributed or reinvested is part of systematic risk and therefore mostly captured in stock-specific betas and in the implied risk premium. We also regard the estimated growth rate of earnings as capable of reflecting differential earnings retention policies.

10 Whaley (2008) provides an account of how the VIX index is related to stock prices. Typically, the relationship is inverse but during prolonged 'bull' markets there is a positive relationship in the run up to market 'corrections'. We include the VIX in the discounting of the near-term earnings only and we assume that the long-run historical average of the VIX can be used for discounting the 10-year ahead projected earnings.
} 
The BW sentiment index can be regarded as relevant to growth perceptions because a number of its components relate to conditions such as IPO activity that usually coincide with growth phases. Baker and Wurgler (2007) discuss in some detail how their index performs through the economic cycle and how well it reflects recessions and booms. It is important to note that we are not claiming that our valuation model is a complete explanation of value at a stock-specific level. Nevertheless, we show that the inclusion of idiosyncratic effects does not greatly alter the significance of the sentiment effect. Our model also accounts for a large fraction of market valuation and the residuals are stationary and not strongly auto-correlated or correlated across stocks. We therefore assume that, despite departures of the stock specific valuations from stock prices, the effects of sentiment are identified on-average at a sector and portfolio level.

For simplicity, the Gordon Growth model (Gordon, 1962) is applied to core earnings from any specific equity as follows:

$$
\mathrm{P}_{t}=\frac{\mathrm{e}_{t}}{r^{e}-g}+\eta_{t}
$$

Where, $\mathrm{P}_{t}$ is the market price per share for a given equity, $\mathrm{e}_{t}$ is core earnings per share, $r^{e}$ is the cost of equity capital for the specific equity concerned. The error term $\eta_{t}$ includes all other drivers of value not captured by the simple model and we permit this be have a moving average representation later since this allows the most recent pricing errors to act as indicators of idiosyncratic effects not captured in the first term. The parameter $g$ will be permitted to be time varying and is given to job of capturing a combination of permanent and transitory nominal earnings growth rates that are not fully captured in near-term 
earnings. This is not the usual interpretation of this model. The Gordon Growth model usually applies to a fixed g that is assumed to apply in perpetuity. However, it is easy to show that any variable growth path that contains an eventual permanent component can be approximated by this representation. Of course, in this case we must be careful to interpret the $g$ as more than just a steady-state long-run growth rate. It will inevitably include short term growth unless the earnings level is close to the permanent component of earnings. To some extent this can be made more consistent with long-run earnings by using longer-term forecasts of earnings but we abstract from this detail ass reliable long-term forecasts of earnings are not readily available.

The basic model above can easily be expanded to produce a more deconstructed version. For example, the growth rate of earnings, $g$, can be made a function of expectations of long-run real macroeconomic growth and inflation (SPF 10-year ahead forecasts of average annual real GDP growth and 10-year ahead forecasts of average annual CPI inflation). Clearly, these macroeconomic variables will not fully explain growth innovations at a firm specific level so there will be an implicit error term in the growth relation. The error term is called implicit because the parameters of the model (including the growth sub-equation) will be chosen to minimise a metric based on the price equation error term, $\eta_{t}$. If the only source of error in the model was due to unexplained growth then a relatively simple transformation of the price equation error can be shown to be an exact function of the growth equation error. It should also be clear that the inclusion of an MA process in the pricing equation itself can be interpreted as including such a process in the growth subequation. Thus the growth sub-equation (with the implicit error process excluded) will be:

$$
g_{t}=\alpha_{0}+\alpha_{1} \mathrm{RGDP}_{10}+\alpha_{2} \mathrm{CPI} 10_{t}
$$


We return later to a more detailed discussion concerning how the model can be estimated. Clearly, the estimated growth term is not guaranteed to be positive but this merely reflects what is omitted from the model. We have chosen to tolerate some degree of negativity in the implied growth since there are many possible reasons for such an outcome when a stripped-down model such as this is designed to capture mostly macroeconomic growth effects and when other aspects of value are ignored (such as changes in the valuation of fixed assets or sudden and unexpected debt-overhang). However, we did find that the inclusion of an MA error process in the model mitigates this problem.

The required return on equity will be time varying as monetary policy is adjusted to counteract inflation expectations and other economic fluctuations. We use SPF projections of medium and long term Treasury bill rates in different parts of the valuation exercise as shown below. But, in terms of sentiment effects, we make the discount rate a function of short-horizon sentiment effects related to market volatility. We consider the following representation for this variable.

$$
r_{t}^{e}=\boldsymbol{r}_{t}^{f}+\beta \text { market risk premium }
$$

Where $\boldsymbol{r}_{t}^{f}$ is the risk free rate of return (specifically the SPF expectations of future Treasury bill rates) and $\beta$ is the aforementioned 'forward-looking' option-implied stock-specific sensitivity to market-wide risk proposed by Chang et al. (2012) or else a beta forecast based on a 'realized beta' (i.e., a beta constructed using realized covariance and variance). A 
time subscript is included in future beta notation. We assume that the risk premium can be represented by the VIX index multiplied by a standardizing constant ' $Q$ ' and an ex ante beta that transfers VIX-risk to excess return required by the average investor. The VIX index reflects both risk aversion changes and fluctuations in the perceived amount of risk. The more general required return expression is therefore:

$$
r_{t}^{e}=\boldsymbol{r}_{t}^{f}+\beta_{t} Q V I X_{t}
$$

We use a further modification of the Gordon growth formula so that permanent growth applies only after period 2 . This takes account of the fact that we have IBES earnings forecasts in respect of Fiscal Year 1 (FY1) and Fiscal Year 2 (FY2). The main 'without' sentiment valuation equation we estimate is as follows: ${ }^{11}$

$$
\begin{aligned}
& \mathrm{P}_{t}=\hat{V}_{t}=\frac{\mathrm{FY} 1_{t}}{\left(1+\boldsymbol{r}_{t}^{f}+\boldsymbol{Q} \beta_{t} \mathrm{VIX}_{t}\right)^{a}}+
\end{aligned}
$$

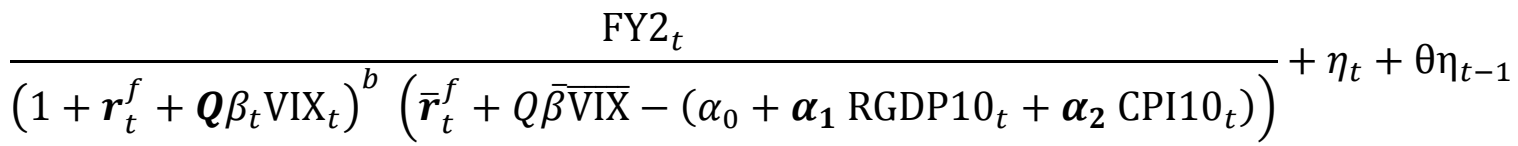

Where:

$P_{t}=$ Market price per share for a specific equity at time t;

$\widehat{V}_{t}=$ fitted fundamental value per share for a specific equity at time $t$;

$F Y 1_{t}=I B E S$ current fiscal year 'core' earnings per share forecasts (where the most recent or next annual earnings are forecasted each month);

11 We take natural logs of both sides when estimating the relation and assume an additive regression error which implies a random proportional error between price and value if the error is small enough that $\ln (1+$ error $) \approx$ error. 
$F Y 2_{t}=I B E S$ next fiscal year (or two year ahead) 'core' earnings per share forecasts (annual); $r_{t}^{f}=$ Survey of Professional Forecasters' 3-month T-bill rate for the current year; $\bar{r}_{t}^{f}=$ Survey of Professional Forecasters' 3-month T-bill rate (expected 10-year average); $\beta_{t}=$ an ex ante, option-implied, stock-specific, time-varying beta; VIX $X_{t}=$ the VIX index provided by the Chicago Board of Trade represents the ex ante, amount of market risk implied by S\&P500 one-month ahead options. We assume that investors expect the VIX to return to its long run average in the very long term and this enters the last term in the denominator. The long run value for this $\overline{V I X}$ is set equal to its historical median $=18.88$ as described by Whaley (2008);

$R G D P 10_{t}=$ Real GDP long-term growth expected. This is based on the SPF forecast of 10 year average real GDP growth;

$C P I 10_{t}=$ long-term growth in prices expected. This is based on the SPF forecast of 10 year average inflation expectations;

$\alpha_{0,1,2}=$ parameters describing the equity-specific growth level expected on average over the whole sample and the implicit relation between variation in firm-level long-term growth in earnings and expected 10-year Real GDP growth and CPI inflation;

$Q=$ a number to be solved-out that will represent the equilibrium price of systematic risk; $a$ and $b$ are the appropriate exponents for discounting FY1 and FY2 respectively, the required number of months from the forecast date to the date of recognizing the earnings in annual accounts (we divide the required rate of return by 12 so that it applies to monthly time value adjustments, not shown in the formula for clarity in the exposition). ${ }^{12}$

\footnotetext{
${ }^{12}$ The model does not have Fama \& French or momentum factors. In an earlier version of this study, available as a working paper, we tested whether the inclusion of such factors had any material effect on the conclusions. Since the effects were minor we have not included these.
} 
We now consider the issue of growth-related sentiment effects. We use an investor sentiment index taken directly from the work of Baker and Wurgler (2006) to augment the basic valuation model. The index (the orthogonalized version) is a linear combination (principal factor) of six investor sentiment measures that are cleaned of their relation with macroeconomic variables. The index fluctuates around zero, which is not necessarily a neutral level of sentiment, but is likely to be a close approximation to it. Baker and Wurgler describe their index as an indicator of the propensity to speculate and they describe how this propensity more readily expresses itself in the prices of stocks that are difficult to value. They add (p. 1,648);

"in the case of young, unprofitable, extreme growth stocks the lack of an earnings history combined with the presence of apparently unlimited growth opportunities allows unsophisticated investors to defend, with equal plausibility, a wide spectrum of valuations, from much too low to much too high, as suits their sentiment. During a bubble period, when the propensity to speculate is high, this profile of characteristics also allows investment bankers (or swindlers) to further argue for the high end of valuations. By contrast, the value of a firm with a long earnings history, tangible assets, and stable dividends is much less subjective, and thus its stock is likely to be less affected by fluctuations in the propensity to speculate."

We include growth-related sentiment effects as an explanatory variable in the longrun growth sub-equation. The motivation for including sentiment in the growth equation is (i) to allow for the effects of cheaper funding, and higher likelihood of investment and expansion actually occurring, when sentiment is high as described in Yuan (2005), and (ii) to allow 'exuberance' or 'gloom' to behaviourally infect expectations of growth when sentiment is very high or very low. This may be associated with investors' confusion between short-term growth and long-term earnings growth. Thus, the model 'with sentiment' has the following form, where $S$ is the sentiment index, $\tilde{V}$ is the 'with' sentiment valuation: 


$$
\begin{aligned}
& \mathrm{P}_{t}=\tilde{V}_{t}=\frac{\mathrm{FY} 1_{t}}{\left(1+\boldsymbol{r}_{t}^{f}+\boldsymbol{Q} \beta_{t} \mathrm{VIX}_{t}\right)^{a}}+ \\
& \frac{\mathrm{FY} 2_{t}}{\left(1+\boldsymbol{r}_{t}^{f}+\boldsymbol{Q} \beta_{t} \mathrm{VIX}_{t}\right)^{b}\left(\overline{\boldsymbol{r}}_{t}^{f}+\boldsymbol{Q} \beta_{t} \overline{\mathrm{VIX}}-\left(\boldsymbol{\alpha}_{\mathbf{0}}+\boldsymbol{\alpha}_{\mathbf{1}} \mathrm{RGDP} 10_{t}+\boldsymbol{\alpha}_{2} \mathrm{CPI} 10_{t}+\boldsymbol{\alpha}_{3} S_{t}\right)\right)}+\eta_{t}+\theta \eta_{t-1}
\end{aligned}
$$

The growth effects arising from sentiment can be ascertained directly from the size and significance of the sentiment parameter. The contribution of sentiment to perceived growth can be assessed comparing the estimated implied growth rates when sentiment is included and excluded, at a firm, sector and market level. The valuation effects can also be assessed by simply comparing the valuations 'with' and 'without' sentiment. The magnitude of these effects clearly depend ( $\mathrm{r}^{\mathrm{e}} \mathrm{g}$ ). We evaluate these effects in the results section and examine how past bubbles and the recent crisis can be described.

There are many ways that the model chosen above can be changed and these could alter the results radically. In the results section we conduct a number of robustness checks to ensure that some obvious alterations do not change our basic conclusions. The robustness analysis is carried out for the following alterations to the above model; changing the value of the $Q$ parameter, estimating the $Q$ parameter for each individual firm rather than imposing a fixed value, changing from forward looking betas to forecasted realized betas, changing the way the VIX index is modified to make it smoother before inclusion in the model, changes in the number of lags in the MA process in the pricing equation, ....

So far we have not mentioned robustness checks for changes in the growth subequation. It is obvious that the growth relation is very stylized and, except for the BW sentiment index and the implicit MA process, it only includes very long run forecasts for 
macroeconomic variables. While there is room for robustness checks with regard to the choice of sentiment index and the number of lags in the implicit MA process, we make the assertion that it important to maintain a strong prior regarding what are permissible growth related variables. Since the sentiment variable by its nature (and despite being made orthogonal to a range of individual macroeconomic variables) will, by sheer chance, possess correlation with short-term macroeconomic variables (and their combinations) it will eventually be possible to swamp-out any remaining role for the sentiment variable if one includes a range of growth proxies. This will defeat the objective of the current exercise which is to merely to assess whether already strong econometric relationships between earnings and macroeconomic forecasts can be significantly improved by the inclusion of a variable that is designed to specifically represent investor sentiment movements. However we conduct some assessments of how changing the horizon of the macroeconomic forecasts affects our results.

We also advise against the use of an AR representation in the pricing equation because this will reintroduce sentiment effects through the lagged price (the use of a small number of MA terms does not produce this effect to the same extent). It is already wellknown that lagged prices will out-perform any purely fundamentals-based valuation but including lagged price gives us no new information. Given that fundamentals-based valuations are so variable it would make good 'Bayesian' sense to give them a smaller weight than past prices when forming posterior beliefs about future warranted prices. Despite the noisiness of the signal based on fundamentals it is still possible to assess whether there is any predictive power in the fundamental valuation. To achieve this we turn to time series econometric methods. 


\subsection{Cointegration and Error Correction}

The estimate of stock valuation i.e., the fitted value from the regression allows us to consider how its changes affect subsequent changes in value. More directly, if the estimated intrinsic value is in-fact cointegrated with market value then divergence between the predicted value and the market price can be treated as a disequilibrium that will be corrected on average over time by price changes or valuation changes (or both) to restore equilibrium. Econometrically, this error correction term should be a significant driver of market returns if we are to conclude that the fundamental valuation drives price rather than vice-versa. This is also a way to test for overt-fitting biases. If the fit is solely produced by excess complexity this will fail to significantly improve the predictive ability of the implied disequilibrium term. Testing for such effects is an approach taken by previous studies (e.g., Campbell and Schiller, 1988a and 1988b, and Lee et al. 1999). It is also common in the macroeconomic literature on wealth effects and budget constraints, such as, Lettau and Ludvigson (2001), Whelan (2008) and Sousa (2010). Previous studies in the finance field often rely on the lagged price-to-earnings or lagged book-to-market ratio as a disequilibrium variable driving returns. But these ratios are often very dependent on a single observation and they are often too variable to be a good indicator of what is truly a long-run disequilibrium effect. In contrast, the valuation errors from the valuation model above are more appropriate as an ECM term since they are based on capitalizing more than just a single observation of earnings or a single BV observation. 
We extend the error correction methodology to encompass disequilibria from the two main equations for valuation (the 'with' and 'without' sentiment cases). We estimate the following ECM representation for returns:

$\ln \Delta P_{t}=\theta_{i} \ln \Delta P_{t-1-i}+\phi_{i} \ln \Delta \widehat{V}_{1, t-i}+\lambda_{i} \ln \Delta \tilde{V}_{2, t-i}+\pi_{1} E C M_{1, t-1}+\pi_{2} E C M_{2, t-1}$

Where:

$i=1$ to $\mathrm{n}$ depending on significance of parameters and until a white noise error is obtained;

$\ln \Delta \widehat{V}_{1, t-i}$ is the recent log changes in fitted values from the 'without-sentiment' valuation equation;

$\ln \Delta \tilde{V}_{2, t-i}$ is the recent log changes in fitted values from the 'with-sentiment' valuation equation;

$E C M_{1, t-1}$ is the lagged error term from the 'with-sentiment' regression (since the regressions are conducted in logs the error can be interpreted as a disequilibrium in the $\mathrm{P} / \widehat{V}$ ratio);

$E C M_{2, t-1}$ is the lagged gap between the valuation with and without sentiment (where the error can be interpreted as a disequilibrium in the $\widehat{V} / \tilde{V}$ ratio);

$\theta_{i}, \phi_{i}$ and $\pi$ are coefficients to be estimated.

In our empirical analysis we test the residuals from the two basic valuation equations for stationarity using standard augmented Dickey-Fuller test restrictions. We also examine whether the ECM regression gives rise to a significantly negative estimates of $\pi_{i, i=\{1,2\}}$. Negative coefficients imply that stock returns act to re-equilibrate the relationship between market price and the with-sentiment valuation as well as to reflect the deviation between the 'with' and 'without' sentiment valuations. From this we can ascertain whether 
market price adjusts more quickly to undo sentiment disequilibrium rather than fundamental disequilibrium. It is plausible that this re-equilibration is not well determined as an average relation but we leave the pursuit of a "threshold" error correction model for future exploration.

\section{DATA}

Our analysis is applied to the DOW 30 stocks (specifically the DOW 30 members on $30^{\text {th }}$ July 2004 with index weights shown in Table 1). The sample runs from January 1996 to Sep 2010. This period includes the dot-com bubble and collapse, the market reaction to the events of 9/11 2001, the steady years of the Great Moderation and the effects of the recent financial and economic crisis that followed the sub-prime mortgage of late 2007 (often called "The Great Recession"). Despite these very different economic conditions we find a remarkably consistent fit for most of the sample.

For these stocks we obtain the end-of-month price per share and the consensus IBES forecasts of earnings per share. IBES earnings forecasts are 'core earnings' forecasts that ignore many contributions to earnings that are transitory, such as surprise income from the sale of assets, asset revaluations or unusual additions to goodwill. IBES earnings forecasts are up-dated at monthly frequency. However, these forecasts relate to future horizons that change only on an annual basis. The IBES earnings forecasts for a representative member of the DOW 30 are illustrated in Figure 1. The significant jumps occur when the forecast horizon moves from one year-end to another. The FY1 forecast is focused on the next annual earnings report, which can be after the end of the year to which the earnings report pertains. For example, if the year-end is December but the release date of the earnings 
report is the following March, then the FY1 forecast in December will have an information horizon which is three months beyond the date of the forecast but a value recognition date which is contemporaneous. Likewise, the forecast made in January will often refer back to the year that has just ended in December, but for which data has not yet been released. Once the official audited earnings data for the previous year is released the FY1 forecast (such as that made in April) will be for the year ending the following December, a forecast horizon of 8 months. The FY2 forecasts refer to the earnings that are to be released in the year ending 12 months after the FY1 year-end. Thus, the maximum distance of the forecast horizon from the date of forecasting is 20 months in the case of FY2.

The two main SPF variables used in our analysis are the forecast for the 10-year average growth in real GDP and the forecast for 10-year annual average inflation expected.13 The average 10-year ahead annual growth rate expected in real GDP over the sample period is $2.8 \%$. The average 10 -year ahead CPI is $2.25 \%$. These variables are not updated at a monthly frequency (they are quarterly). We simply carry forward the most recent quarterly observations to fill-out the missing months. Our valuation is based on nominal earnings and price per share.

We obtained the VIX index from the Chicago Board of Trade at a monthly frequency. The historical median of this index is 18.88 , which is the long-run value assumed to apply in the growth sub-equation (denoted as $\overline{V I X}$ in equation 1 ). Conventional estimation of beta is backward-looking, based on historical data used in the context of the one factor CAPM. In a recent paper, Chang, Christoffersen, Jacobs and Vainberg (2012) argue that computation of time-varying, historic-based betas, or even betas based on 'realized' covariance, represent a

13 The SPF data is freely available from the Federal Reserve Bank of Philadelphia's web library, http://www.philadelphiafed.org/research-and-data/real-time-centre/survey-of-professional-forecasters/ 
second best solution. Rather, they propose a method for estimating forward-looking betas from information that is embedded in options prices. Using the single factor CAPM they express the forward looking beta as a function of the implied variance and implied skewness from the distributions of individual stock and index option prices. We make use of the estimates of Chang et al. (2012), simply regarding them as an exogenous input into our analysis. These are available at a daily frequency, but we take the end of month observations.

We obtained the investor sentiment index developed by Baker and Wurgler (2007) directly from Jeffrey Wurgler's web library. There are two version of this index and we use the one that is based on components that are orthogonalized with respect to a number of macroeconomic variables. As Baker and Wurgler acknowledge, there are no definitive or uncontroversial measures of investor sentiment. Nevertheless, they base their index on a principal components analysis of six well known indicators from previous work by other authors. These include (i) the closed-end fund discount (CEFD), (ii) NYSE share turnover, (iii \& iv) the number and average first-day returns on IPOs, (v) the equity share in new issues, and (vi) the dividend premium. They discuss in detail how each of these indicators is expected to relate to sentiment. While this index is not necessarily equal to zero for neutral sentiment, for expositional purposes, we make this convenient assumption. We chose this measure of investor sentiment in preference to survey based measures to avoid potential endogeneity issues.

We have so far assumed that the VIX index and the BW sentiment indicator provide different information. It is interesting to note that these indicators are indeed quite different in their dynamics and that they little correlation with each other. We find that the 
correlation coefficient between the levels of these variables was 0.23 and the correlation in their first differences was 0.05 . Only about $7 \%$ of the variation of the BW Sentiment Index is explained by variation in the VIX index. While there is scope for argument regarding which of these indexes is more appropriately assigned to the risk-aversion and growth-related aspects of valuation, we have made an informed judgment on this issue largely related to the rationale behind the variables that are included in the BW sentiment index. In our view, the constituents of the BW index are related to growth and the perceived barriers to such growth. The assignment we use also gives more robust results across the full sample of stocks for the full period concerned.

\section{ESTIMATION PROCEDURES \& RESULTS}

In this section we briefly discuss how the model is estimated and show some graphical information about the main outputs of the modeling. We show the proportional contribution of sentiment to valuation of the DOW 30 and of sub-sectors of the market over time based on aggregating the effects at an equity-specific level. We then present and discuss regression results and robustness checks in more detail and following this we proceed to the testing of differences in growth and valuation errors depending on the inclusion of sentiment effects. The significance of the regression results and the post regression tests indicate that sentiment has important effects on perceptions of growth prospects. We create an index of the valuation effects of sentiment using relative implied growth rates at a market-wide level and for various sectors. We graphically display a number of other important and interesting auxiliary variables. These include the ex ante 
implied risk premium and the implied long-term growth rate of earnings. We discuss how these variables evolve over time during significant events and in relation to sentiment.

\subsection{Estimation}

All results were obtained by application of nonlinear least squares estimations that were carried out using the 'NLLS' routine in the RATSC software package. ${ }^{14}$

\section{2. $\quad$ Price-Value Relation (Full Sample)}

The important outputs from the regression results associated with equations (2) and (3) are presented in Table 2. These results pertain to regression analysis using the full sample of data. We return later to results from a rolling regression based on available data at each date. In all cases we show the standard error (or significance level) associated with parameter estimates (test statistics) below the point estimate in parentheses. In the case of equation (2), we present the following;

(i) the estimated risk aversion parameter, ' $Q$ ';

(ii) the estimated partial derivative of Gordon growth with respect to sentiment, $\frac{d g}{d s}$;

(iv) stationarity tests on the residuals from this regression (specifically, ADF tests based on Dickey and Fuller, 1979 assessed with critical values from MacKinnon, 1996).

The table also reports results of tests as follows:

(i) a test for the statistical validity of restricting the risk aversion parameters to be equal to 0.015 (approximately the average of the stock-specific estimates);

\footnotetext{
${ }^{14}$ The RATS code is available from the authors on request.
} 
(ii) a test for the exclusion of the Fama-French and momentum factors (where a more general model was estimated to perform the test).

Finally, in the case of equation (3) - the ECM regression - we report the following:

(i) the ECM parameter estimates $\pi_{1}$ and $\pi_{2}$;

(ii) the adjusted R-squared for the returns regression.

It can be seen from the results reported in Column 1 of Table 2 that the estimated risk aversion parameter, $\mathrm{Q}$, is significantly positive in most cases and has a magnitude that is consistent with a reasonably sized risk premium. In the one case where it is negative it is statistically insignificantly different from zero. The average size of $Q$ is approximately 0.015 . The risk premium is the product of $Q$ and the VIX index (divided by 10) so we can conclude that the implied risk premium is approximately $3.5 \%$ on average. ${ }^{15}$ The cross-stock variation in estimated $Q$ is not large once certain outliers are excluded. There are 15 stocks with estimates for Q lying between 0.011 and 0.019. Figure 2 shows the ex ante risk premium implied by $Q=0.015$, which is simply multiplied by the VIX index.

The effect of sentiment is given by the estimate of the derivative $\frac{d g}{d s}$ which is shown in Column 2 of Table 2 (evaluated at average values of GDP10 and CPI10). This shows the point estimate of the effect of sentiment on the long-run growth in earnings. ${ }^{16}$ This has the expected positive sign in 25 cases and it is highly statistically significant in 19 cases. The

\footnotetext{
${ }^{15}$ Chang et al. (2012) refer to the potential presence of slight bias in their forward looking betas when they compare them with other beta measures such as the realized beta (see Andersen, Bollerslev, Diebold and Wu, 2006). So the implied premium may be understated slightly.

16 The 'summarize' function in RATS allows post-regression evaluation of combinations of coefficients and produces standard errors for these combinations.
} 
range of values for this parameter is quite large (with $1^{\text {st }}$ and $3^{\text {rd }}$ quartiles equal to 0.055 and 0.57 respectively). This variability probably reflects the differential effects of sentiment due to different firm characteristics as described by Baker and Wurgler (2007). We would expect well established manufacturing firms to be less affected by sentiment and firms in new growth sectors to be more affected. A view of the growth effects that are implied by the 'with' and 'without' sentiment regressions can easily be seen by plotting the terms

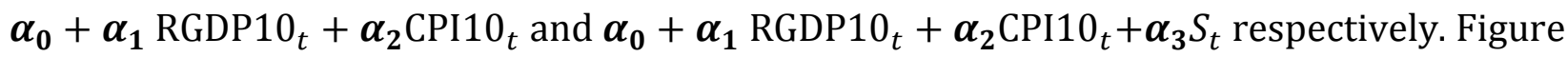
3 shows these implied growth rates for the Finance stocks, Technology stocks and other stocks over the sample. This confirms the fact that sentiment contributes significantly to implied growth (particularly around the dot-com period) and it also shows that Finance and Tech stocks were more prone to these effects. The divergence between growth rates implied by the 'with' sentiment valuation and that implied by the 'without' sentiment valuation begins in early 1999. The peak of the 'with' sentiment implied growth rate series occurs a year after the collapse of the dot-com bubble in March 2000.

Table 2, Column 3 shows the ADF test results for the residuals from equation (1). Cointegration is a concept that is not well established in the context of non-linear relations. However, after capitalization of earnings it is plausible that the underlying price-value relation is linear implying that the residuals from the main regression should be stationary and amenable to stationarity testing in the usual way, and that an error correction representation is also valid. Much of the sensitivity of residual based tests of cointegration concerns the number of variables in the relation and whether there is a constant and trend in the cointegrating relation. We have been rigorous in not allowing any constant or trend in the estimation of equation 2. Assuming the basic underlying relation is linear, we use 
critical values for the ADF test of stationarity of the residuals from equation 2 based on the work of MacKinnon (1996). ${ }^{17}$ We find that all of the regressions have residual series that can be rejected as non-stationary at the $5 \%$ level of significance or better. We conclude from this that the price and fitted value based on equation 2 are cointegrated. The same conclusion can be made about the difference between the fitted values from the 'with' and 'without' sentiment versions of the model, but we omit this result from Table 1 for clarity of exposition. At a 'meta' level there is strong evidence for cointegration using this valuation approach.

Column 4 in Table 2 reports results for the tests of the restriction that the stockspecific risk aversion parameter is equal to 0.015 , which is the average of the estimates from all stocks. This test statistic is Chi-Square distributed under the null of acceptance. We find that the restriction is rejected in 17 cases. Importantly however, we found that there was very little impairment of the growth effects of sentiment even when the restriction was imposed. ${ }^{18}$ Column 5 contains test results for the joint exclusion of Fama-French and Momentum factors. The exclusion of these factors is jointly accepted in two-thirds of cases.

The results from estimation of equation (3) are presented in columns 6 to 8 of Table 2. In column 6 we report the parameter estimate on the lagged price/value ratio, where the

\footnotetext{
${ }_{17}$ We use estimates of $1 \%, 5 \%$ and $10 \%$ critical values for ADF, from MacKinnon 1996, with N=1, assuming no constant or trend in the cointegrating relation. For any sample size $\mathrm{T}$, the estimated critical value is $\beta_{\infty}+\beta_{1} / T+\beta_{2} / T^{2}$ where the following table provides the required parameters and the ADF critical values (cv) used in our analysis in the final column:

\begin{tabular}{|r|c|c|c|c|}
\hline \multicolumn{1}{|l|}{ Level } & $\beta_{\infty}$ & $\beta_{1}$ & $\beta_{2}$ & \multicolumn{1}{l|}{ ADF cV } \\
\hline $1 \%$ & -2.5658 & -1.96 & -10.04 & -2.58662 \\
\hline $5 \%$ & -1.9393 & -0.398 & & -1.94332 \\
\hline $10 \%$ & -1.6156 & -0.181 & & -1.61743 \\
\hline
\end{tabular}

${ }^{18}$ In earlier versions of this paper we imposed a common risk aversion parameter based on the estimated risk aversion in the case of an "easy-to-value" stock. We picked the "easy-to-value" stock using characteristics suggested by Baker and Wurgler (2007). The results were not qualitatively different from what we present here.
} 
value is from the 'with' sentiment regression. We expect this parameter to have a negative sign and this is confirmed in 27 cases out of 30 . However, only a small number of these are significantly negative using the MacKinnon critical values (there are two coefficient estimates that are significantly negative at the $10 \%$ level, 3 at the $5 \%$ level and 2 at the $1 \%$ level). Thus, it is difficult to find strong evidence that market price adjusts in response to this implied mis-valuation at a stock-specific level. However, with the vast majority of coefficients negative it is likely that there is a significant error correction effect at a portfolio level. The $7^{\text {th }}$ column reports the results for the other error correction term (the lagged deviation between the 'with' sentiment valuation and the 'without' sentiment valuation). In this case the results is slightly weaker, with 22 negative estimates only 3 of which are significant using the MacKinnon critical values. Once again however, at a 'meta' level, we regard this as evidence in favour of re-equilibration in respect of this disequilibrium.

Overall, there is evidence that both of the disequilibria are reversed by appropriately signed future returns, but the effect is not strong. However, it should be noted that the effect may be difficult to identify as an average relation. If there are infrequent 'corrections' responsible for re-equilibration then the ECM parameter estimates may not fully reflect this since they are based on an average relation present over the whole sample. We present the $\bar{R}^{2}$ from the ECM regression in the last column. Twenty five of these are positive, with 16 greater than $5 \%$ and 7 that are above $10 \%$. While it is desirable to have good predictive power in the ECM regression this is not a necessary condition for obtaining a good indicator of the valuation effects of sentiment (which is a 'levels' rather than 'returns' concept). Since the ECM term and the other variables are given in percentage terms the speed of error 
correction from the ECM parameter estimates can be inferred. The median value of the ECM parameters estimates on both ECM terms is approximately -0.05. If the disequilibria are on average $10 \%$ of price, then returns adjustment each period may be as great as $0.5 \%$ of the price level. The longer term adjustment can be assessed by regressing lower frequency returns on past disequilibrium but we leave this for future work.

\subsection{Valuation Effects of Sentiment}

The valuation effects of sentiment are very apparent when the two fitted valuations and the price are presented graphically. Figure 4 shows this for the case of HewlettPackard. Clearly, the stock market price during the period of the dot-com bubble is not well tracked by the pure fundamentals based valuation. Once the investor sentiment variable is allowed to interact with the valuation metric we get better fits for this period. Such sentiment effects can be detected in a number of specific cases. Figure 5 shows the 'with' and 'without' valuations for different sectors and for the market as a whole. The Finance and Technology sectors, for example, are well tracked by the sentiment valuation and there is a significant difference between the 'with' and 'without' sentiment valuations in these cases. In the case of 'other stocks' the sentiment effect is less perceptible.

To obtain an aggregate (or sector-specific) valuation effect from sentiment we

calculate the weighted sum of $(\tilde{V} / \hat{V})$ for the stocks of interest (where the weights are the DOW index weights). This measure shows how sentiment contributes to over- and undervaluation in a proportional sense. Since the 'with' sentiment valuation can overshoot stock price it is important to interpret the measure just proposed as a stochastic variable that embodies a frontier somewhere near its local average. Based on a visual inspection of the 
equity-specific relative valuations, the 'with' sentiment valuation is mostly between the 'without' sentiment valuation and price when the two valuations are most different from each other. We make some tentative suggestions later regarding what can be considered to be a 'significant' gap between the two valuations.

Figure 5 shows the effects of sentiment on valuation for the case of Finance stocks, Technology stocks, other stocks and DOW30 stocks. An important conclusion is that the valuation effects that can be attributed to sentiment are quite large. When the sentiment index is at its peak, the valuation effect attributable to sentiment for Technology and Finance stocks is about $50 \%$ in excess of the 'without' sentiment valuation. The largest effects are in the Finance sector. The stocks denoted as 'other' are not greatly endowed with value attributable to sentiment. It is also important to note that the valuation effects attributable to sentiment can be negative. This is true of the last 3 quarters of 2002 and most of 2003 for the Finance stocks.

Based on this index of value attributable to sentiment, the dot-com bubble does not show-up until relatively late, and when it appears it is relatively strong. According to this measure the beginning of the dot-com bubble is apparent from November 1999 when the index of value attributable to sentiment (Finance sector) first breached 1.10. It quickly rose to approximately 1.30 in December 1999. This elevated reading lasted until the end of March 2000, and is often cited as the date of the bursting of the dot-com bubble. The index then declined for a 2-month period to near normal levels before rising again to almost 1.65 in August 2000. This return to elevated levels confirms views expressed by Shiller (2000) that the market was still unrealistically priced in late 2000 despite the large market correction earlier in the year. A decline to more normal levels occurred again in March of 
2001. We also note that this index temporarily declined again in September 2001 to 0.91 following the 9/11 attacks. But the effect was short-lived until about 6 months later when sentiment was low again and the valuations of sentiment-prone stocks were particularly negatively affected.

The tardy signal regarding the appearance of the dot-com bubble produced by the valuation ratio may reduce its appeal as an early warning indicator. However, an analysis of the implied growth rates looks more promising. Also, a careful analysis of the components of the valuation equation indicate an increasing potential for larger than average movements relating to sentiment. The early 1999 divergences between implied growth rates ('with' and 'without' sentiment) give an earlier warning of mis-valuation than the comparison of the 'with' and 'without' sentiment valuations. This reflects the fact that growth rate variability feeds through as smaller valuation effects if at the same time interest rates rise. The larger is the gap between the interest rate (plus the risk premium) and the implied growth rate, the smaller will be the effect of an increase in expected growth on value. We therefore consider whether the relative implied growth rates themselves could act as an early warning indicator. Figure 6 shows the relative growth rates implied by the 'with' and 'without' sentiment valuations (analogous to the valuation ratios shown in Figure 5). This shows that the relative growth attributable to sentiment was on the rise in mid 1999. It also indicates that implied growth was largely sentiment driven in the early 1990s for the DOW as a whole.

An advantage of using the implied growth rates in statistical terms is that growth rate estimates are likely to have simpler statistical properties than the valuations. This facilitates construction of a significance level for the rejection of the hypothesis that the 
'with' sentiment implied growth is different from the 'without' sentiment implied growth. While such a test is not a measure of how different the valuations are under the two models, it is likely to be easier to reject them as similar the larger is the magnitude of the gap. The implied growth rates are restrained to be positive, since we square the growth subequation during estimation. Under the null hypothesis of no difference between the 'with' and 'without' sentiment implied growth rates, we can regard the ratio of the average estimated growth rates from the 'with' and 'without' sentiment valuations as a ratio of quasi Chi-Squared distributed variables, which produces a ratio that is F-distributed under the null. This in-turn allows us to make statements with statistical confidence regarding the likelihood of sentiment effects being present. For the case of the DOW, there are 30 observations in each period and therefore the F-statistic will be $F(30,30)$ distributed under the null. Smaller groupings of stocks (such as Finance stocks) will obviously lead to Fstatistics with fewer degrees of freedom and this reduces the confidence with which the null hypothesis of 'no difference between valuations' can be rejected.

The significance levels for the F-statistics based on the ratio of average implied growth rates from the two valuations and for different groups of stocks are presented in Figure 7. The smaller is the significance level the higher the level of confidence with which we can say the valuations are different. We include the $10 \%$ bar in the plots to show when the null hypothesis can be rejected with more than $90 \%$ confidence. We can observe from the first of these plots that the dot-com bubble is associated with a rejection of similarity between the valuations with $90 \%$ confidence. This occurs as early as September 1999 for the tests based on the DOW 30. Whatever about the prescience of this measure it is clear that when the significance level reaches virtually zero and remains there for a long time this 
should be taken as a clear signal that the 'with' and 'without' valuation differences are very unusual and should either produce arbitrage or prompt policy initiatives to bring valuations more in line with fundamentals.

\subsection{Out-of-Sample Results}

In this section we give a heuristic account of an out-of-sample analysis. While such an analysis is fraught with difficulty due to the non-linear, complex and unstable nature of the underlying relationship, we present it as an insightful exercise. To get an indication as to how sentiment variation may translate into valuation effects in real time we conduct the 'with' sentiment regression for an initial sample running from January 1996 to December 1999 and obtain one-step-ahead fits for the following components of the valuation equation; (i) implied growth, (ii) the required return on equity and (iii) the valuation fit. Thus, we base the fit on the value of the explanatory variables in the period ahead using the parameter estimates derived from a regression using a sample that predates this period. We then roll the regression forward each period recalculating the parameters (when possible) and deriving a one-step-ahead fit for the same three components for the next period.

An analysis of the components of the valuation equation reveals how the valuation fit sometimes behaves in an unstable way due to a high sensitivity to movements in $g$ when $r^{e}-g$ is close to zero. Indeed, it is possible for predictions of $g$ to exceed the predicted required return on equity. This produces a negative valuation fit. This is not just an issue for the out-of-sample context. When parameter estimates are based on a short enough sample, large outliers will also give rise to in-sample negative valuation fits for which the taking of 
logs is an invalid operation given that our regression fits log of price with the log of value. The best course of action in this case is to drop the offending observations from estimation until a sufficient number of new observations are available with which to obtain nonnegative valuation fits. We know from the original analysis above that this happens for all periods when the sample is large enough. As it turns out, the problem of negative one-stepahead forecasts of value occurs mostly for those firms that are most prone to sentiment effects and it often takes a large number of new observations to be included before the problem is solved.

While it may seem that dropping observations from estimation is a deficiency of the methodology presented here we do not consider it so. When the out-of-sample prediction produces $g>r$ this outcome is informative even when the estimates upon which the prediction is based are a little out-of-date. What it indicates is that sentiment effects are likely to cause problems for agents in ascertaining the underlying value of stocks. It tells us that the valuation exercise in such circumstances is very sensitive to changes in the drivers of growth or required return on equity. If a large part of predicted growth is attributable to sentiment then this should act as a warning that the market is becoming prone to significant sentiment effects. It signals a need to monitor how the increased fragility of the market is feeding into risk aversion and predicted volatility.

Figure 8 (panel A) presents out-of-sample predictions of growth and required return on equity implied by the estimated parameters from equation 2 . The gap between required return and growth is shown in panel $\mathrm{B}$. We use a weighted average of the growth and required return predictions for the case of a portfolio of non-finance and non-technology stocks (those stocks where the problem of dropped observations just discussed is not 
prevalent). This reveals a sharp rise in the expected growth in Jan 2000 when there was a spike in investor sentiment. Over the periods that follow, the regression is updated and since sentiment levels remained relatively high, the estimated responsiveness of growth to sentiment declines (to ensure a better fit). Predicted growth therefore falls progressively for a number of periods. Nevertheless, the gap between growth and required return remains relatively small and a second wave of sentiment drives predicted growth up again towards the beginning of 2001. The gap between expected growth and required return remains small for most of 2001 after which there is a return to more normal levels. Predicted valuations (untabulated) are often very large relative to market valuation during periods when there is a small gap between required return and growth. It might be expected that the VIX would rise in these circumstances but we did not find this to be the case. A rise in the VIX would have helped to stabilize valuations because the required premium would then have compensated for the measurable increase in risks associated with outstanding growth predictions based largely on sentiment movements. The lack of a reaction of this type remains somewhat puzzling and could have been viewed by policy makers as a signal of a market failure.

\section{CONCLUSION}

We use a well-known and widely accepted valuation metric and two different types of sentiment indicators as a basis for improving the measurement of the valuation effects of sentiment. This enables us to apply non-linear regression techniques to fit the price-value relation 'with' and 'without' sentiment. Our empirical analysis uses ex ante variables throughout. These include forecasts of macroeconomic variables, options-based measures of risk and forward-looking betas. We apply restrictions during estimation that maintain 
credible projections for growth rates and required rates of return. Moreover, we identify two indexes of the value-relevance of sentiment and show how they can be assessed in statistical terms.

We find that a large proportion of market valuation can be attributed to sentiment. This shows that sentiment effects are more pervasive than usually understood. While the dot-com boom is identified as a period of excessive exuberance, sentiment effects are shown to extend well beyond that episode. An out-of-sample analysis shows that the projections for growth can exceed projected required rates of return when there are spikes in sentiment and we argue that this is informative for macroeconomic policy management. By breaking down projections into components relating to growth and required return for risk, it is easier to identify when sentiment effects and policy changes will have most effect. We find that growth related sentiment effects show up sooner than the actual valuation effects and we therefore recommend this to macro-prudential regulators as a workable early warning indicator. 


\section{ACKNOWLEDGMENTS}

We are grateful to Kris Jacobs (McGill University) and his co-authors for permitting us to use their option-implied betas. We are also grateful for constructive comments on earlier version of this paper from participants of seminars at Queen's University, Trinity College Dublin, University of Bath and the Central Bank of Ireland. We would also like to acknowledge helpful comments from Philip Hamill, Julien Idier, Ian Tonks and Karl Whelan. We also thank KX-Systems and First Derivatives, for providing software. 


\section{REFERENCES}

Abarbanell, J., and Lehavy, R., 2003, "Biased Forecasts or Biased Earnings? The Role of Reported Earnings in Explaining Apparent Bias and Over/Underreaction in Analysts' Earnings Forecasts", Journal of Accounting and Economics, 36, 105-146.

Adrian, T., and Franzoni F., 2009, "Learning about Beta: Time-Varying Factor Loadings, Expected Returns, and the Conditional CAPM", Journal of Empirical Finance, 16(4), 537556.

Adrian, T., and Shin, H.S., 2008, "Liquidity, Monetary Policy and Financial Cycles", Current Issues in Economics and Finance, 14(1).

Agnello, L., and Schuknecht, L., 2009, "Booms and Busts in Housing Markets: Determinants and Implications", Working Paper Series 1071, European Central Bank.

Alessi, L., and Detken, C., 2009, "Real Time Early Warning Indicators For Costly Asset Price Boom/Bust Cycles - A Role For Global Liquidity", Working Paper Series 1039, European Central Bank.

Andersen, T. G., Bollerslev, T., Diebold, F.X., and Wu, J., 2006, "Realized Beta: Persistence and Predictability", Econometric Analysis of Financial and Economic Time Series / Part B, Fomby, T., Terrell, D., (Eds), Advances in Econometrics, 20, 1-39.

Baker, M., and Wurgler, J., 2006, "Investor Sentiment and the Cross Section of Stock Returns", Journal of Finance, 61, 1645-1680.

Baker, M., and Wurgler, J., 2007, "Investor Sentiment in the Stock Market", Journal of Economic Perspectives, 21(2), 129-151.

Baker, M., Wurgler, J., and Yuan., Y., 2012, "Global, Local, and Contagious Investor Sentiment", Journal of Financial Economics, forthcoming.

Benartzi, S., and Thaler, R., 1995, "Myopic Loss Aversion and the Equity Premium Puzzle", Quarterly Journal of Economics, 110, 73-92.

Bernanke, B., and Gertler, M., 2001, "Should Central Banks Respond to Movements in Asset Prices?", American Economic Review (Papers and Proceedings), 91(2), 253-257.

Bordo, M.D., and Jeanne, O., 2002, "Boom-Busts in Asset Prices, Economic Instability, and Monetary Policy", NBER Working Paper, 8966.

Brunnermeier, M.K., 2001, "Asset Prices under Asymmetric Information: Bubbles, Crashes, Technical Analysis and Herding", Oxford University Press. 
Buss, A., Schlag, C., and Vilkov, G., 2009, “CAPM With Option-Implied Betas: Another Rescue Attempt", Goethe University Finance Department Working Paper, SSRN: http://ssrn.com/abstract=1342988.

Campbell, J.Y., and Shiller, R., 1988a, "Cointegration and Tests of Present Value Models", Journal of Political Economy, 95, 1062-1088.

Campbell, J.Y., and Shiller, R., 1988b, "The Dividend-Price Ratio and Expectations of Future Dividends and Discount Factors", Review of Financial Studies, 1, 195-228.

Campbell, J.Y., and Vuolteenaho, T., 2004, “Bad Beta, Good Beta”, American Economic Review, 94(5), 1249-1279.

Campbell, S.D., and Diebold, F.X., 2009, "Stock Returns and Expected Business Conditions: Half a Century of Direct Evidence", Journal of Business and Economic Statistics, 27(2), 266-278.

Chang B., Christoffersen P., Jacobs, K., and Vainberg, G., 2012, "Option Implied Measures of Equity Risk", Review of Finance, 16(2), 385-428.

Ciciretti, R., Dwyer, G.P., and Hasan, I., 2009, "Investment Analysts' Forecasts of Earnings", Federal Reserve Bank of St. Louis Review, 91, 5(2), 545-567.

Chung, S.L., and Yeh, C.Y., 2009, "Investor Sentiment, Regimes and Stock Returns", National Taiwan University Working Paper, SSRN: http://ssrn.com/abstract=1342588.

Coudert, V., and Gex, M., 2007, "Does Risk Aversion Drive Financial Crises? Testing the Predictive Power of Empirical Indicators", CEPII Working Paper No. 2007-02.

Detken, C., and Smets, F., 2004, "Asset Price Booms and Monetary Policy”, Working Paper Series 364, European Central Bank.

Dickey, D.A., and Fuller, W.A., 1979, "Distributions of the Estimators for Autoregressive Time Series with a Unit Root", Journal of the American Statistical Association, 74, 427431.

Easton, P., and Sommers, G., 2007, "Effect of Analysts' Optimism on Estimates of the Expected Rate of Return Implied by Earnings Forecasts", Journal of Accounting Research 45, 983-1015.

Engle, R.F., and Granger, C., 1987, "Cointegration and Error-Correction: Representation, Estimation, and Testing", Econometrica, 55, 531-554. 
Epstein, L.G., and Schneider, M., 2008, "Ambiguity, Information Quality and Asset Pricing", Journal of Finance, 63(1), 197-228.

Fama, E.F., and French, K.R., 1993, "Common Risk Factors in the Return on Stocks and Bonds", Journal of Financial Economics, 33, 3-56.

Fama, E. F., and French, K.R., 1998, "Value versus Growth: The International Evidence", Journal of Finance, 53, 1975-1999.

Fong, W.F., 2012, “Do Expected Business Conditions Explain the Value Premium?”, Journal of Financial Markets, 15, 181-206.

Gerdesmeier D., Reimers, H., and Roffia, B., 2009, "Asset Price Misalignments and the Role of Money and Credit", European Central Bank Working Paper No. 1068. SSRN: http://ssrn.com/abstract=1429265.

Gordon, M., 1962, "The Investment, Financing and Valuation of the Corporation", Irwin, Homewood, IL.

Haugen, R.A., and Baker, N.L., 1996, "Commonality in the Determinants of Expected Stock Returns", Journal of Financial Economics, 41(3), 401-439.

Haugen, R.A., and Baker, N.L., 2009, "Case Closed, the Handbook of Portfolio Construction: Contemporary Applications of Markowitz Techniques", John B. Guerard Jn., ed.

Hirshleifer, D, 2001, "Investor Psychology and Asset Pricing", Journal of Finance, 56(4),1533-1597.

Kumar, A., and Lee, C., 2006, "Retail Investor Sentiment and Return Comovements", Journal of Finance, 61, 2451-2486.

Kumar, M.S., 2007, "Do the Diversification Choices of Individual Investors Influence Stock Returns?", Journal of Financial Markets, 10(4), 362-390.

Kumar, M.S., and Persaud, A., 2002, "Pure Contagion and Investors' Shifting Risk Appetite: Analytical Issues and Empirical Evidence", International Finance, 5(3), 401-436.

Kumar, P., Srescu, S., Boehme, R., and Danielsen, B., 2008, "Estimation Risk, Information, and the Conditional CAPM: Theory and evidence", Review of Financial Studies, 21, 10371075.

Lee, C., Myers, J., and Swaminathan, B., 1999, "What is the Intrinsic Value of the Dow?", Journal of Finance, 54(5), 1693-1741. 
Lemmon, M.L., and Ni, S.X., 2008, "The Effects of Investor Sentiment on Speculative Trading and Prices of Stock and Index Options", HKUST Working Paper, SSRN: http://ssrn.com/abstract=1306237.

Lettau, M., and Ludvigson, S., 2001, "Consumption, Aggregate Wealth and Expected Stock Returns", Journal of Finance, 41(3), 815-849.

Machado, J.A., and Sousa, J., 2006, "Identifying Asset Price Booms and Busts with Quantile Regressions", Working Paper No. 8, Banco de Portugal.

MacKinnon, R., 1996, "Numerical Distribution Functions for Unit-Root and Cointegration Tests", Journal of Applied Econometrics, 140, 719-752.

Miller, M.H., and Modigliani, F., 1961, "Dividend Policy, Growth and the Valuation of Shares", Journal of Business, 34, 411-433.

Miller, M., and Rock, K., 1985, "Dividend Policy under Asymmetric Information", Journal of Finance, 40, 1031-1051.

Newey, W., and West, K., 1987, "A Simple Positive-Definite Heteroscedasticity and Autocorrelation Consistent Covariance Matrix", Econometrica 55, 703-708.

Rhodes-Kropf, M., Robinson, D., and Viswanathan, S., 2005, "Valuation Waves and Merger Activity: The Empirical Evidence", Journal of Financial Economics 77, 561-603.

Sharpe, S., 2002, "Re-Examining Stock Valuation and Inflation: The Implications of Analysts' Earnings Forecasts", Review of Economics and Statistics, 84(4), 632-648.

Shiller, R., 2000 \& 2005, "Irrational Exuberance", $1^{\text {st }}$ and $2^{\text {nd }}$ Eds. Princeton University Press. Stambaugh, R.F., Yu, J.F., and Yuan, Y., 2012, "The Short of it: Investors Sentiment and Anomalies", Journal of Financial Economics, forthcoming.

Sousa, R. M., 2010, “Consumption, (Dis)-Aggregate Wealth and Asset Returns", Journal of Empirical Finance, 17(4), 606-622.

Whaley, R. E., 2008, “Understanding VIX”, mimeo: http://ssrn.com/abstract=1296743.

Whelan, K., 2008, "Consumption and Expected Asset Returns without Assumptions about Unobservables", Journal of Monetary Economics, 55(7), 1209-1221.

White, H., 1980, "A Heteroscedasticity-Consistent Covariance Matrix Estimator and Direct Test for Heteroscedasticity", Econometrica, 48, 817-838. 
Yuan, K., 2005, "Asymmetric Price Movements and Borrowing Contraints: A Rational Expectations Equilibrium Model of Crisis, Contagion and Confusion", Journal of Finance, 60(1), 379-411.

Yu, J.F., and Yuan, Y., 2011, "Investor Sentiment and the Mean-Variance Relation", Journal of Financial Economics, 100, 367-381. 


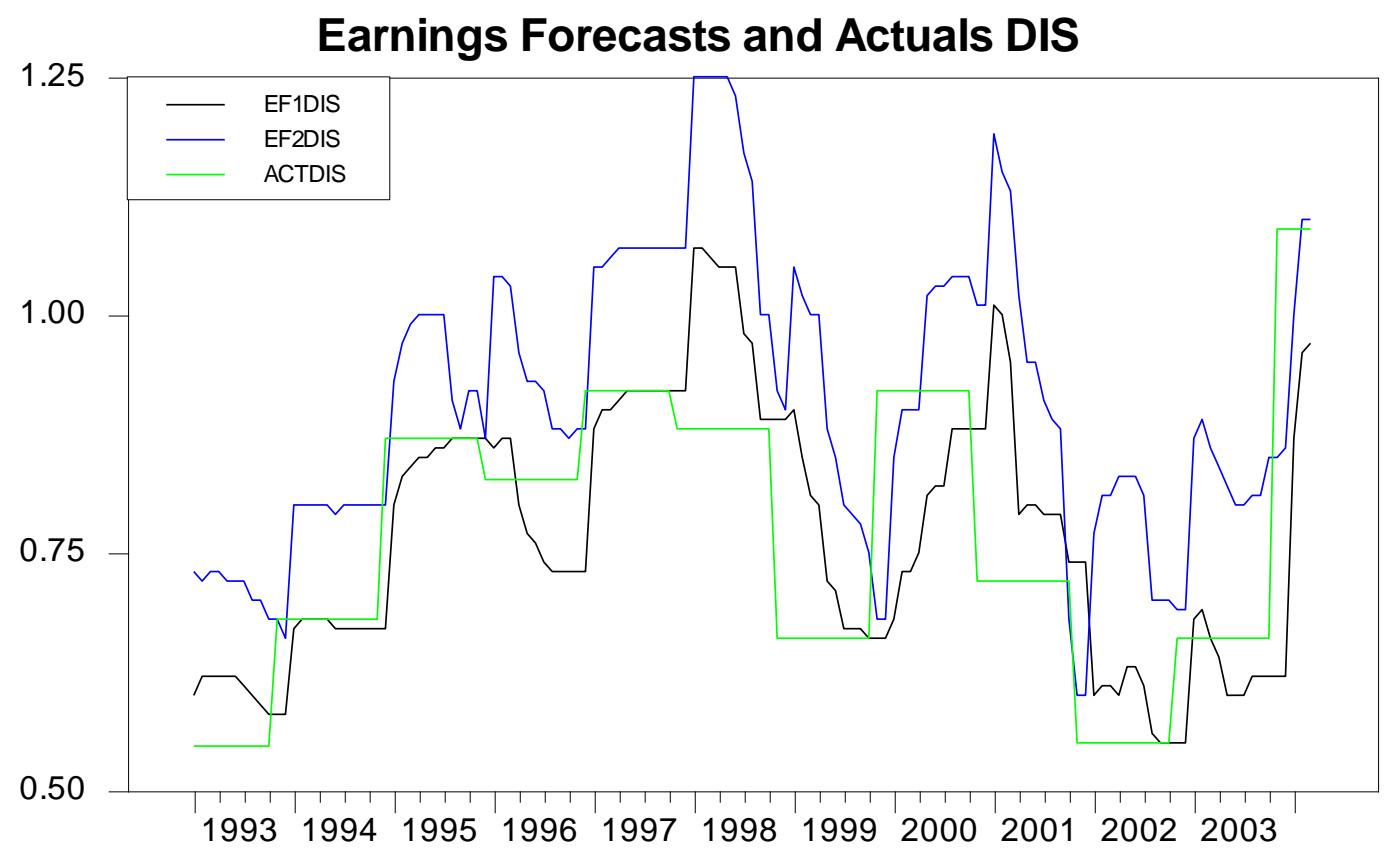

Figure 1. DIS Inc (Disney). EF1 and EF2 denote IBES Earnings Per-Share (EPS) forecasts for the current year (or if not yet released, the most recent year) and for the following year-end respectively. ACT denotes the actual reported earnings. The reported EPS are adjusted for stock splits so that the old numbers are directly comparable with EPS figures most recently available for DIS. 


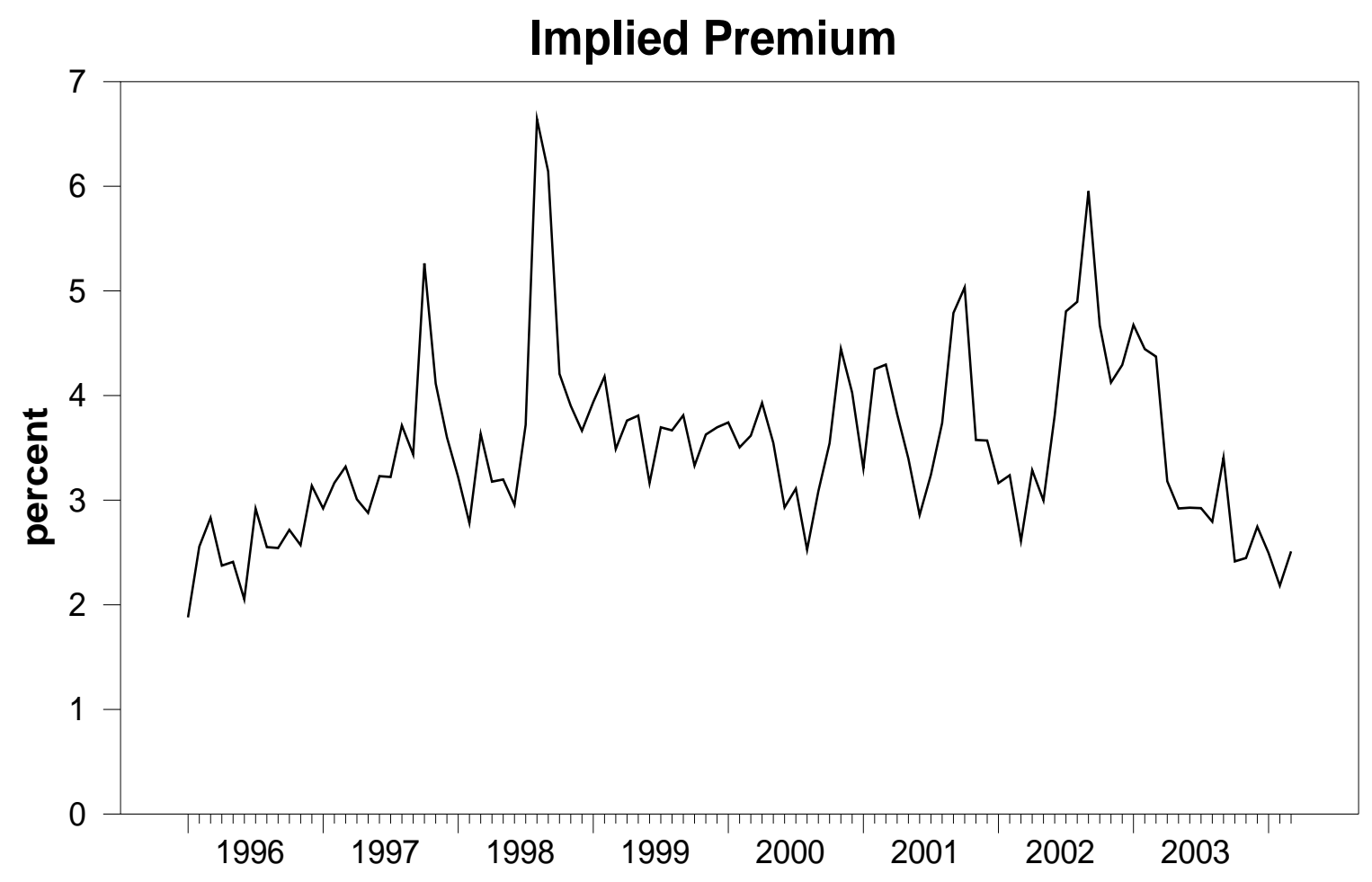

Figure 2. The ex ante premium associated with $\mathrm{Q}=0.015$. 


\section{Implied Gordon Growth}
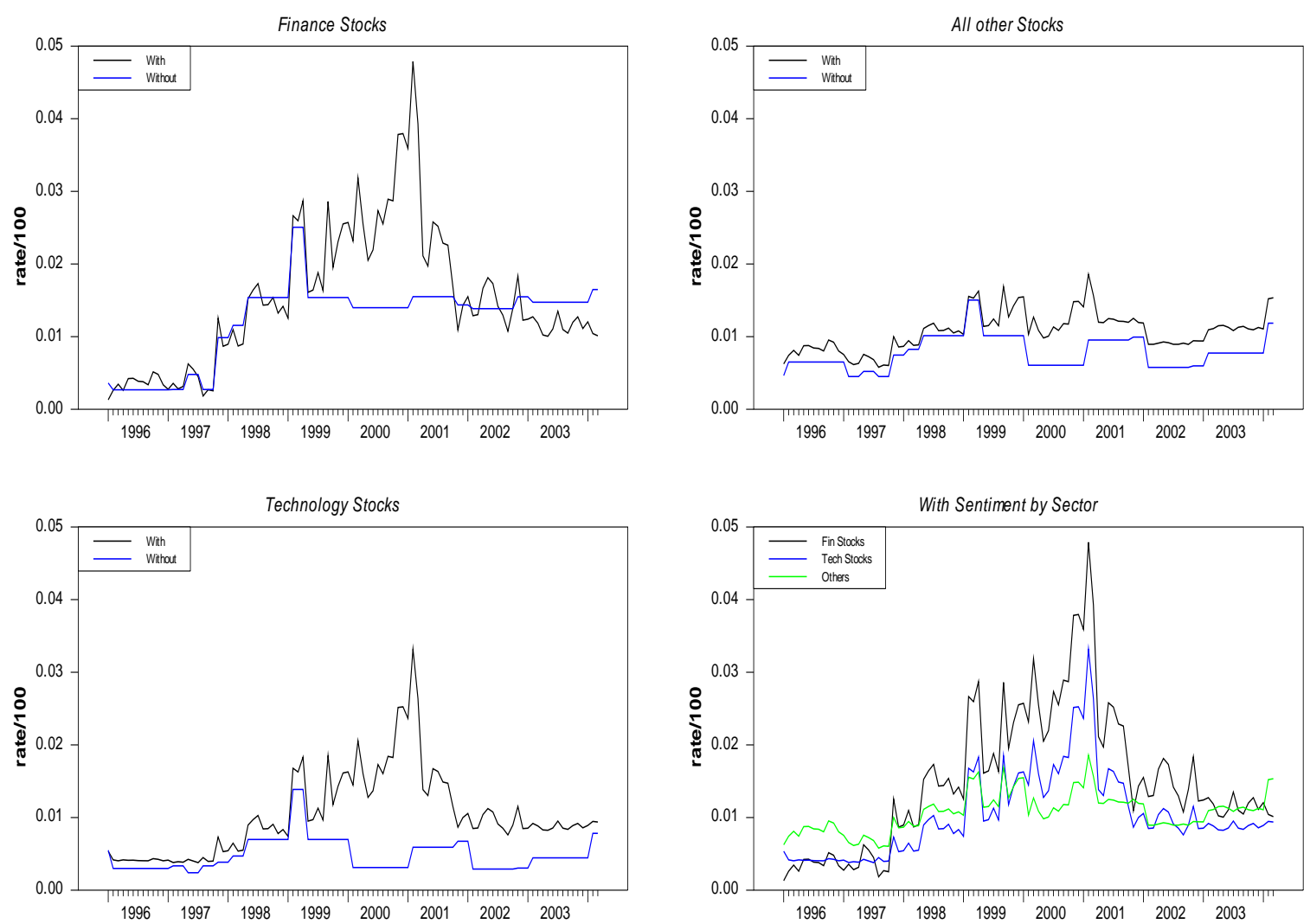

Figure 3. The two graphs in the first column present plots of the weighted averages of the implied growth rates 'with' and 'without' sentiment in each period for stocks within the Finance and Technology sectors (the weights are the index weights). The top graph in the second column reports the same variable for all other stocks in the Dow 30. The lower graph in the second column reports plots of the implied growth rates for the three sectors 'with' sentiment. 


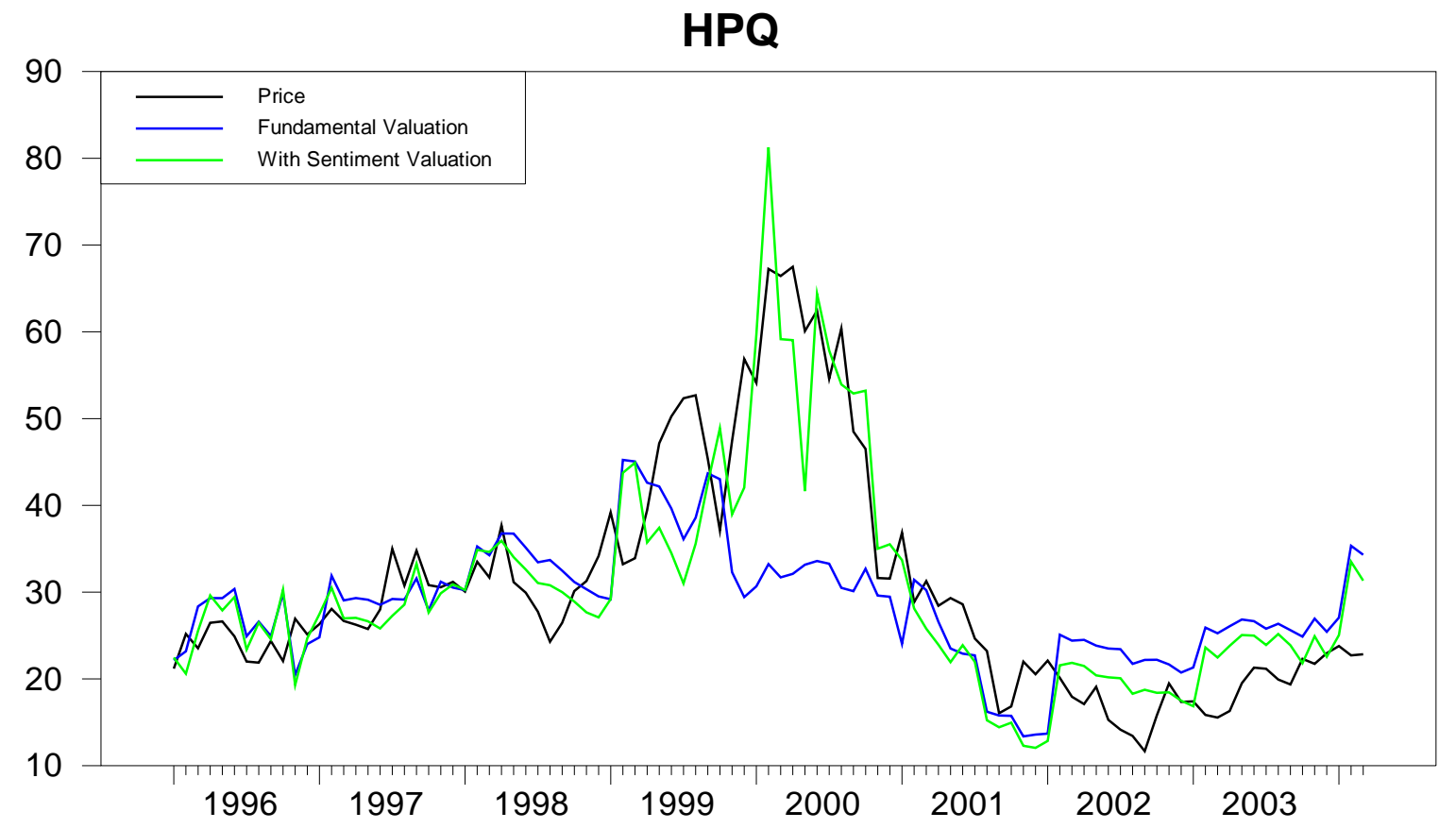

Figure 4. An example of valuations 'with' and 'without' sentiment. The Price per share of Hewlett-Packard stock and the valuation per share based on fundamentals alone and based on investor sentiment in addition to fundamentals. 


\section{Index of Value Attributable to Sentiment}
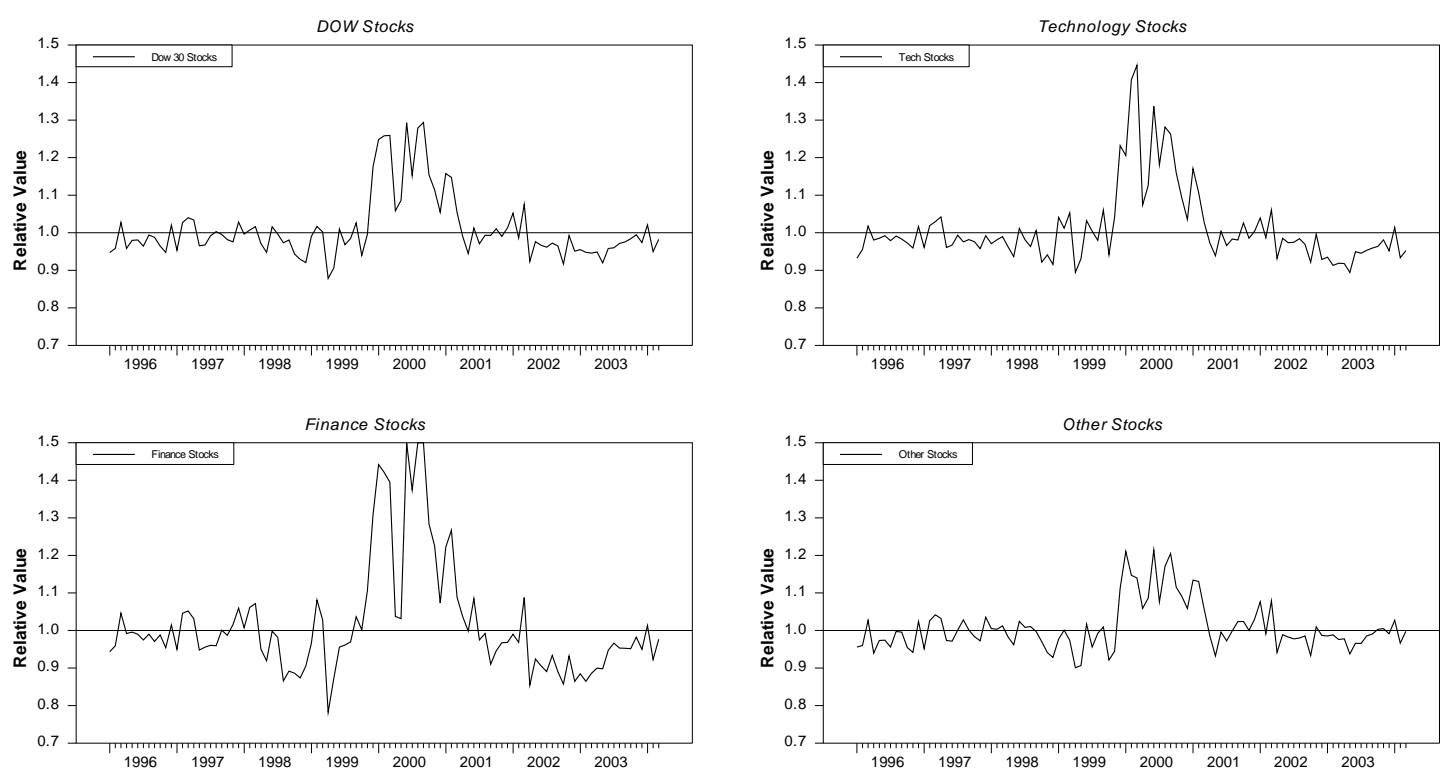

Figure 5. These plots show the average of 'with' sentiment valuation relative to the 'without' sentiment valuation for Finance, Technology, Other Stocks and the DOW 30. The weighted averages are based on the DOW 30 weights.

\section{Index of Implied Growth Attributable to Sentiment}
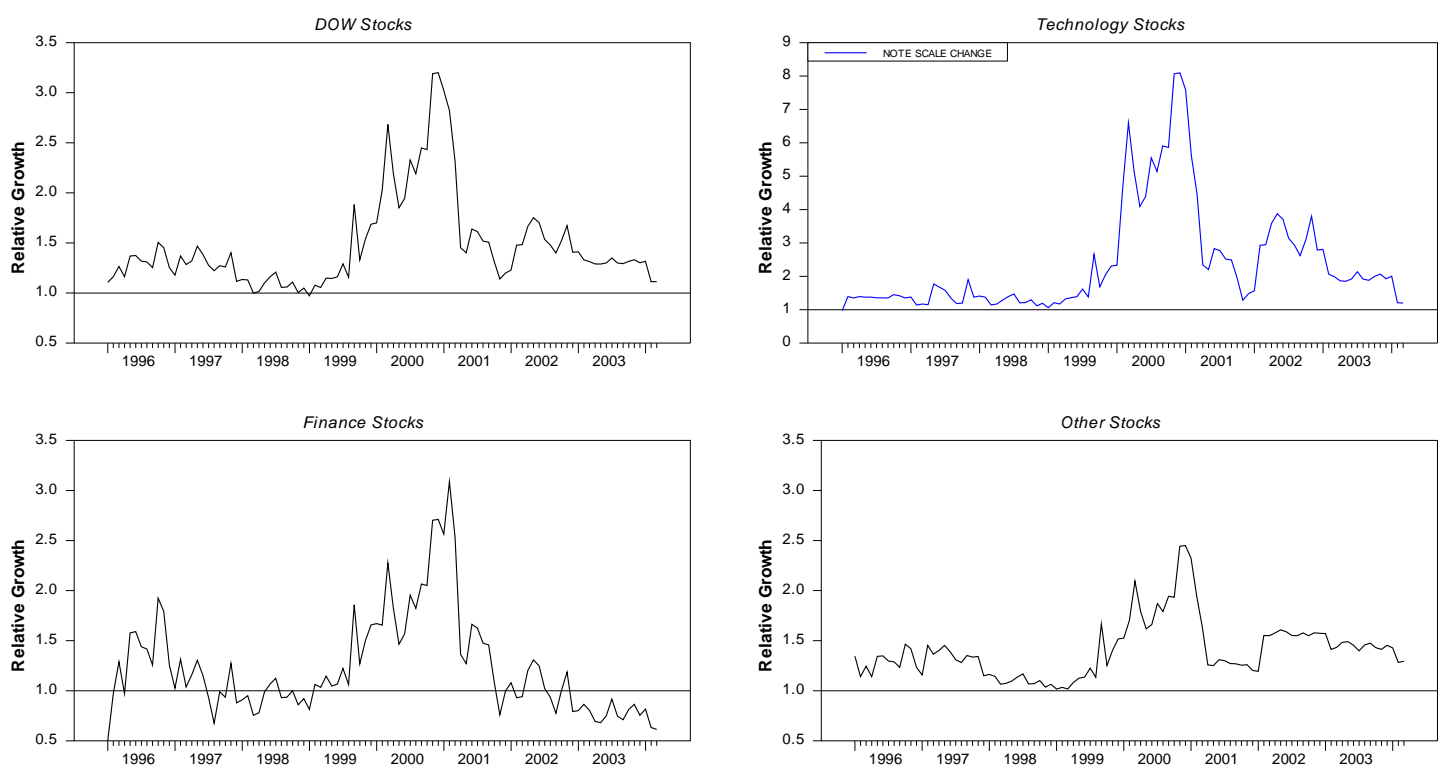

Figure 6. These plots show the average of 'with' sentiment implied growth relative to the 'without' sentiment implied growth for Finance, Technology, Other Stocks and the DOW 30. The weighted averages are based on the DOW 30 weights. Note the change of scale for the case of Technology stocks. 


\section{Significance Level for Ratio of Implied Growth Rates}

\section{Null Hyp: Equal Implied Growth Rates}
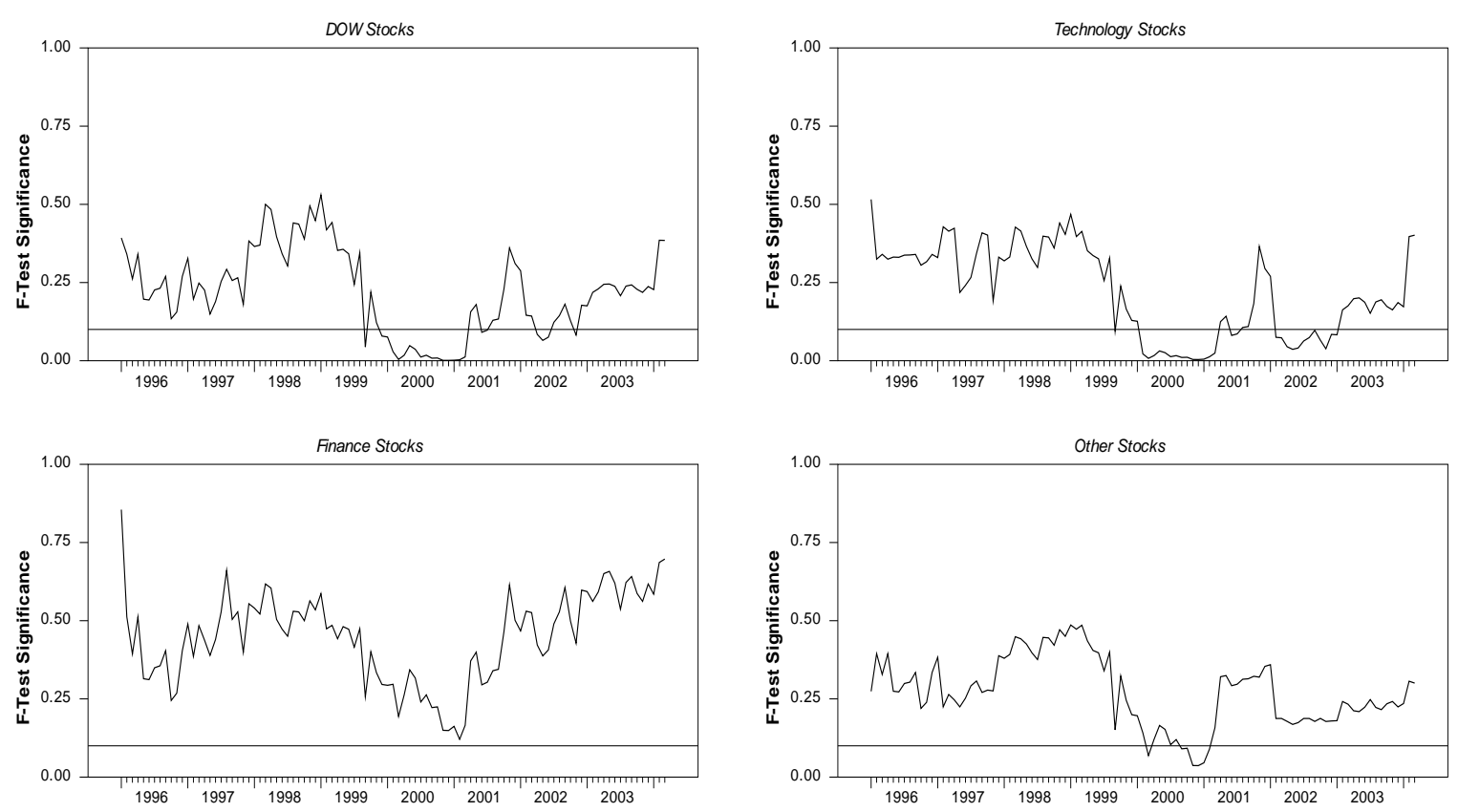

Figure 7. These plots show the significance levels for the ratio of 'with' and 'without' sentiment implied growth rates for Finance, Technology, Other Stocks and DOW 30 stocks. The 0.10 line is given as a benchmark for rejecting the hypothesis of no difference between the implied growth rates. The degrees of freedom for the tests are dependent on the number of stocks used to obtain the average each period (DOW $=30$, Finance $=5$, Technology $=8$, Other $=17$ ). 


\section{A:Out-of-sample r \& g}
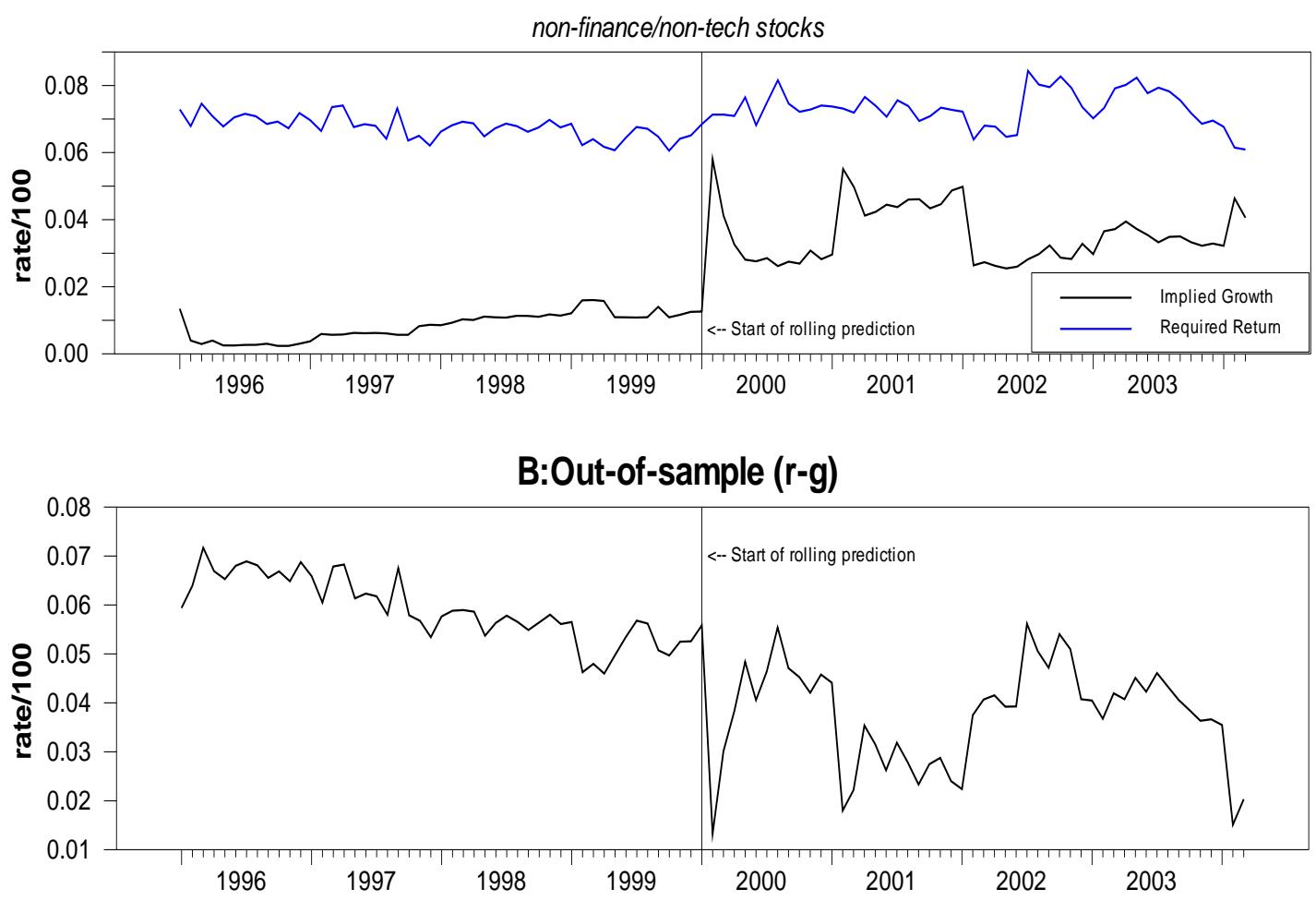

Figure 8: For the case of non-financial firms and non-technology firms we show the weighted average of the implied growth and the required rate of return based on parameter estimates from the regression based on equation (2). The pre-sample period is January 1996 to December 1999. The regression is rolled forward to include available information before the one-step-ahead predictions are calculated. Panel A shows the predicted growth and required return separately. Panel B shows the gap between required return and predicted growth. 
Table 1. Sample composition and weights

\begin{tabular}{ll|ll}
\hline Ticker & Name (Index weight) & Ticker & Name (Index weight) \\
\hline AA & ALCOA INC (2.31) & HON & HONEYWELL (2.57) \\
AIG & AMERICAN EXPRESS (3.67) & INTC & INTEL CORP (1.89) \\
BA & AMERICAN INTL (5.13) & IBM & IBM (6.24) \\
CAT & BOEING CO (3.55) & JNJ & JOHNSON \& JOHNSON (3.97) \\
JPM & CATERPILLAR (5.50) & MCD & MCDONALDS (1.87) \\
C & J P MORGAN (2.73) & MRK & MERCK \& CO (3.36) \\
KO & CITIGROUP INC (3.28) & MSFT & MICROSOFT (2.05) \\
DIS & COCA COLA CO (3.62) & MMM & 3M CO (6.27) \\
DD & DISNEY WALT CO (1.81) & PFE & PFIZER INC (2.43) \\
XOM & DU PONT (3.12) & MO & ALTRIA GROUP (3.56) \\
GE & EXXON MOBIL (3.21) & PG & PROCTER \& GAMBLE (3.89) \\
GM/MTLQQ & GENERAL ELEC CO (2.27) & T/SBC & AT\&T / SBC COMM INC (1.73) \\
HPQ & GENERAL MTR LIQ CO (3.24) & UTX & UNITED TECH (6.42) \\
HD & HEWLETT PACKARD (1.46) & VZ & VERIZON (2.59) \\
\hline HOTE & HOME DEPOT INC (2.49) & WMT & WAL MART (3.72)
\end{tabular}

NOTE: The table reports the ticker symbols and names for the sample stocks and the index weights as at $5^{\text {th }}$ July 2004. 
Table 2. Regression results

\begin{tabular}{|c|c|c|c|c|c|c|c|c|}
\hline Equity & $\begin{array}{c}Q \\
(1)\end{array}$ & $\begin{array}{l}\frac{d g}{d S} \\
(2)\end{array}$ & $\begin{array}{l}\text { ADF } \\
\text { (3) }\end{array}$ & $\begin{array}{c}\text { Chi-Sq-Test } \\
\{Q ; 0.015\} \\
(4)\end{array}$ & $\begin{array}{c}\text { F-Test } \\
\text { FF-factors } \\
(5)\end{array}$ & $\begin{array}{c}\text { ECM } \\
\pi_{1} \\
(6) \\
\end{array}$ & $\begin{array}{c}\text { ECM } \\
\pi_{2} \\
(7)\end{array}$ & $\begin{array}{l}\text { ECM } \\
R^{2} \\
(8) \\
\end{array}$ \\
\hline Alcoa (AA) & $\begin{array}{c}0.021^{* * *} \\
(0.002)\end{array}$ & $\begin{array}{l}-0.143 \\
(0.131)\end{array}$ & $-4.033^{* * *}$ & $\begin{array}{c}12.83^{* * *} \\
(0.00)\end{array}$ & $\begin{array}{c}1.238 \\
(0.294)\end{array}$ & $\begin{array}{c}-0.032 \\
(0.051)\end{array}$ & $\begin{array}{c}-0.082 \\
(0.322)\end{array}$ & 0.000 \\
\hline Am $\operatorname{Exp}(A X P)$ & $\begin{array}{c}0.015^{* * *} \\
(0.002)\end{array}$ & $\begin{array}{c}0.574^{* * *} \\
(0.092)\end{array}$ & $-3.256^{* * *}$ & $\begin{array}{c}0.023 \\
(0.879)\end{array}$ & $\begin{array}{c}1.174 \\
(0.318)\end{array}$ & $\begin{array}{c}-0.032 \\
(0.053)\end{array}$ & $\begin{array}{c}-0.171^{* *} \\
(0.086)\end{array}$ & 0.057 \\
\hline AIG (AIG) & $\begin{array}{c}0.015^{* * *} \\
(0.002)\end{array}$ & $\begin{array}{c}0.715^{* * *} \\
(0.092)\end{array}$ & $-4.427^{* * *}$ & $\begin{array}{c}0.002 \\
(0.968)\end{array}$ & $\begin{array}{l}2.317^{*} \\
(0.073)\end{array}$ & $\begin{array}{c}-0.048 \\
(0.046)\end{array}$ & $\begin{array}{l}-0.047 \\
(0.055)\end{array}$ & 0.001 \\
\hline Boeing (BA) & $\begin{array}{c}0.013^{* * *} \\
(0.001)\end{array}$ & $\begin{array}{l}0.221^{* *} \\
(0.093)\end{array}$ & $-4.94 * * *$ & $\begin{array}{l}4.146^{* *} \\
(0.042)\end{array}$ & $\begin{array}{c}0.07 \\
(0.976)\end{array}$ & $\begin{array}{c}0.023 \\
(0.054)\end{array}$ & $\begin{array}{c}0.023 \\
(0.206)\end{array}$ & -0.003 \\
\hline Caterpillar (CAT) & $\begin{array}{c}0.027^{* * *} \\
(0.002)\end{array}$ & $\begin{array}{c}-0.822^{++} \\
(0.34)\end{array}$ & $-3.359^{* * *}$ & $\begin{array}{c}33.645^{* * *} \\
(0.00)\end{array}$ & $\begin{array}{l}2.641^{* *} \\
(0.048)\end{array}$ & $\begin{array}{c}-0.066 \\
(0.045)\end{array}$ & $\begin{array}{c}0.084 \\
(0.108)\end{array}$ & 0.009 \\
\hline J P Morgan (JPM) & $\begin{array}{c}0.029^{* * *} \\
(0.003)\end{array}$ & $\begin{array}{c}0.298 \\
(0.193)\end{array}$ & $-4.668^{* * *}$ & $\begin{array}{c}49.025^{* * *} \\
(0.00)\end{array}$ & $\begin{array}{c}0.859 \\
(0.461)\end{array}$ & $\begin{array}{c}-0.101^{*} \\
(0.059)\end{array}$ & $\begin{array}{c}-0.232 \\
(0.213)\end{array}$ & 0.092 \\
\hline City (C) & $\begin{array}{c}0.024^{* * *} \\
(0.002)\end{array}$ & $\begin{array}{l}0.72^{* * *} \\
(0.144)\end{array}$ & $-4.115^{* * *}$ & $\begin{array}{c}13.974^{* * *} \\
(0.00)\end{array}$ & $\begin{array}{l}2.314^{*} \\
(0.074)\end{array}$ & $\begin{array}{c}-0.105^{*} \\
(0.06)\end{array}$ & $\begin{array}{l}-0.032 \\
(0.097)\end{array}$ & 0.038 \\
\hline Coca Cola (KO) & $\begin{array}{c}0.000 \\
(0.002)\end{array}$ & $\begin{array}{c}0.321^{* * *} \\
(0.115)\end{array}$ & $-2.8^{* * *}$ & $\begin{array}{c}76.57^{* * *} \\
(0.00)\end{array}$ & $\begin{array}{c}0.674 \\
(0.568)\end{array}$ & $\begin{array}{c}-0.036 \\
(0.039)\end{array}$ & $\begin{array}{c}-0.003 \\
(0.121)\end{array}$ & 0.045 \\
\hline Disney (DIS) & $\begin{array}{c}0.008^{* * *} \\
(0.002)\end{array}$ & $\begin{array}{c}0.493^{* * *} \\
(0.091)\end{array}$ & $-4.374^{* * *}$ & $\begin{array}{c}11.885^{* * *} \\
(0.001)\end{array}$ & $\begin{array}{c}0.927 \\
(0.427)\end{array}$ & $\begin{array}{c}-0.052 \\
(0.054)\end{array}$ & $\begin{array}{c}-0.07 \\
(0.091)\end{array}$ & 0.009 \\
\hline Du Pont (DD) & $\begin{array}{c}0.012^{* * *} \\
(0.001)\end{array}$ & $\begin{array}{c}0.003 \\
(0.022)\end{array}$ & $-3.078^{* * *}$ & $\begin{array}{c}2.471 \\
(0.116)\end{array}$ & $\begin{array}{l}0.432 \\
(0.73)\end{array}$ & $\begin{array}{c}-0.085^{* *} \\
(0.04)\end{array}$ & $\begin{array}{c}1.867 \\
(4.243)\end{array}$ & 0.039 \\
\hline Exxon (XOM) & $\begin{array}{c}0.011^{* * *} \\
(0.003)\end{array}$ & $\begin{array}{c}0.245^{* * *} \\
(0.063)\end{array}$ & $-3.422^{* * *}$ & $\begin{array}{c}2.018 \\
(0.155)\end{array}$ & $\begin{array}{c}0.156 \\
(0.926)\end{array}$ & $\begin{array}{c}-0.051 \\
(0.042)\end{array}$ & $\begin{array}{c}-0.052 \\
(0.139)\end{array}$ & 0.015 \\
\hline Gen Elect (GE) & $\begin{array}{c}0.012^{* * *} \\
(0.002)\end{array}$ & $\begin{array}{c}1.011^{* * *} \\
(0.099)\end{array}$ & $-3.25^{* * *}$ & $\begin{array}{c}1.531 \\
(0.216)\end{array}$ & $\begin{array}{c}3.819^{* * *} \\
(0.009)\end{array}$ & $\begin{array}{c}-0.018 \\
(0.037)\end{array}$ & $\begin{array}{l}-0.002 \\
(0.04)\end{array}$ & 0.022 \\
\hline Gen Motor (GM) & $\begin{array}{c}0.063^{* * *} \\
(0.005)\end{array}$ & $\begin{array}{l}-0.422 \\
(0.499)\end{array}$ & $-3.921^{* * *}$ & $\begin{array}{c}69.09^{* * *} \\
(0.00)\end{array}$ & $\begin{array}{c}1.41 \\
(0.238)\end{array}$ & $\begin{array}{l}-0.027 \\
(0.034)\end{array}$ & $\begin{array}{c}0.359 \\
(0.284)\end{array}$ & 0.036 \\
\hline
\end{tabular}


Table 2 (continued)

\begin{tabular}{|c|c|c|c|c|c|c|c|c|}
\hline Equity & $\begin{array}{c}Q \\
(1)\end{array}$ & $\begin{array}{l}\frac{d g}{d S} \\
(2)\end{array}$ & $\begin{array}{l}\text { ADF } \\
(3)\end{array}$ & $\begin{array}{c}\text { Chi-Sq-Test } \\
\{Q ; 0.015\} \\
(4)\end{array}$ & $\begin{array}{c}\text { F-Test } \\
\text { FF-factors } \\
\text { (5) }\end{array}$ & $\begin{array}{c}\text { ECM } \\
\pi_{1} \\
(6)\end{array}$ & $\begin{array}{c}\text { ECM } \\
\pi_{2} \\
(7)\end{array}$ & $\begin{array}{c}\text { ECM } \\
R^{2} \\
(8)\end{array}$ \\
\hline Hewlett-Pac (HPQ) & $\begin{array}{c}0.011^{* * *} \\
(0.004)\end{array}$ & $\begin{array}{l}0.584^{* *} \\
(0.248)\end{array}$ & $-3.774^{* * *}$ & $\begin{array}{c}0.86 \\
(0.354)\end{array}$ & $\begin{array}{c}0.413 \\
(0.744)\end{array}$ & $\begin{array}{c}-0.114^{* *} \\
(0.05)\end{array}$ & $\begin{array}{c}-0.076 \\
(0.134)\end{array}$ & 0.064 \\
\hline Home Depot (HD) & $\begin{array}{c}0.009 * * * \\
(0.003)\end{array}$ & $\begin{array}{l}0.84^{* * *} \\
(0.124)\end{array}$ & $-3.132^{* * *}$ & $\begin{array}{c}3.853^{* *} \\
(0.05)\end{array}$ & $\begin{array}{c}0.62 \\
(0.602)\end{array}$ & $\begin{array}{c}-0.019 \\
(0.036)\end{array}$ & $\begin{array}{c}-0.041 \\
(0.051)\end{array}$ & -0.013 \\
\hline Honeywell (HON) & $\begin{array}{c}0.016^{* * *} \\
(0.001)\end{array}$ & $\begin{array}{c}-0.151 \\
(0.115)\end{array}$ & $-5.683^{* * *}$ & $\begin{array}{c}1.305 \\
(0.253)\end{array}$ & $\begin{array}{c}5.064^{* * *} \\
(0.002)\end{array}$ & $\begin{array}{c}-0.118 \\
(0.091)\end{array}$ & $\begin{array}{c}0.085 \\
(0.336)\end{array}$ & 0.099 \\
\hline Intel Corp. (INTC) & $\begin{array}{l}0.004^{* *} \\
(0.002)\end{array}$ & $\begin{array}{c}0.343^{* * *} \\
(0.129)\end{array}$ & $-2.935^{* * *}$ & $\begin{array}{c}23.229^{* * *} \\
(0.00)\end{array}$ & $\begin{array}{c}2.985^{* *} \\
(0.03)\end{array}$ & $\begin{array}{c}-0.081 \\
(0.064)\end{array}$ & $\begin{array}{c}-0.203 \\
(0.165)\end{array}$ & 0.074 \\
\hline IBM (IBM) & $\begin{array}{c}0.016^{* * *} \\
(0.003)\end{array}$ & $\begin{array}{c}0.556^{* * *} \\
(0.141)\end{array}$ & $-3.994^{* * *}$ & $\begin{array}{l}0.206 \\
(0.65)\end{array}$ & $\begin{array}{l}2.645^{* *} \\
(0.047)\end{array}$ & $\begin{array}{c}-0.139 * * * \\
(0.043)\end{array}$ & $\begin{array}{c}0.019 \\
(0.067)\end{array}$ & 0.104 \\
\hline Johnson \& J (JNJ) & $\begin{array}{c}0.006^{* * *} \\
(0.002)\end{array}$ & $\begin{array}{c}0.445^{* * *} \\
(0.054)\end{array}$ & $-2.289^{* *}$ & $\begin{array}{c}26.088^{* * *} \\
(0.00)\end{array}$ & $\begin{array}{c}0.727 \\
(0.536)\end{array}$ & $\begin{array}{c}0.03 \\
(0.05)\end{array}$ & $\begin{array}{c}-0.032 \\
(0.089)\end{array}$ & 0.133 \\
\hline MacDonald (MCD) & $\begin{array}{c}0.015^{* * *} \\
(0.002)\end{array}$ & $\begin{array}{c}0.464^{* * *} \\
(0.098)\end{array}$ & $-3.641^{* * *}$ & $\begin{array}{c}1.157 \\
(0.282)\end{array}$ & $\begin{array}{c}0.147 \\
(0.931)\end{array}$ & $\begin{array}{c}-0.012 \\
(0.052)\end{array}$ & $\begin{array}{l}-0.28^{* *} \\
(0.114)\end{array}$ & 0.101 \\
\hline Merck (MRK) & $\begin{array}{c}0.013^{* * *} \\
(0.003)\end{array}$ & $\begin{array}{c}0.753^{* * *} \\
(0.101)\end{array}$ & $-3.554^{* * *}$ & $\begin{array}{c}0.776 \\
(0.378)\end{array}$ & $\begin{array}{c}0.347 \\
(0.791)\end{array}$ & $\begin{array}{c}-0.016 \\
(0.044)\end{array}$ & $\begin{array}{c}-0.005 \\
(0.074)\end{array}$ & 0.131 \\
\hline Microsoft (MSFT) & $\begin{array}{c}0.004^{* * *} \\
(0.001)\end{array}$ & $\begin{array}{c}0.509^{* * *} \\
(0.106)\end{array}$ & $-4.1^{* * *}$ & $\begin{array}{c}80.901^{* * *} \\
(0.00)\end{array}$ & $\begin{array}{c}1.292 \\
(0.275)\end{array}$ & $\begin{array}{c}-0.073 \\
(0.052)\end{array}$ & $\begin{array}{c}-0.158 \\
(0.114)\end{array}$ & 0.120 \\
\hline 3M (MMM) & $\begin{array}{c}0.006^{* * *} \\
(0.001)\end{array}$ & $\begin{array}{c}0.069 \\
(0.053)\end{array}$ & $-5.011^{* * *}$ & $\begin{array}{c}252.1^{* * *} \\
(0.00)\end{array}$ & $\begin{array}{l}3.197^{* *} \\
(0.022)\end{array}$ & $\begin{array}{c}-0.231^{* * *} \\
(0.075)\end{array}$ & $\begin{array}{c}0.047 \\
(0.326)\end{array}$ & 0.090 \\
\hline Pfizer (PFE) & $\begin{array}{c}0.013^{* * *} \\
(0.004)\end{array}$ & $\begin{array}{c}0.826^{* * *} \\
(0.134)\end{array}$ & $-2.366^{* *}$ & $\begin{array}{c}0.403 \\
(0.525)\end{array}$ & $\begin{array}{c}0.027 \\
(0.994)\end{array}$ & $\begin{array}{c}0.036 \\
(0.027)\end{array}$ & $\begin{array}{c}0.003 \\
(0.047)\end{array}$ & 0.132 \\
\hline Altria (MO) & $\begin{array}{c}0.041^{* * *} \\
(0.004)\end{array}$ & $\begin{array}{c}-0.981 \\
(0.714)\end{array}$ & $-3.229^{* * *}$ & $\begin{array}{c}56.416^{* * *} \\
(0.00)\end{array}$ & $\begin{array}{c}2.453^{*} \\
(0.061)\end{array}$ & $\begin{array}{c}-0.042 \\
(0.046)\end{array}$ & $\begin{array}{c}-0.388 \\
(0.301)\end{array}$ & 0.009 \\
\hline Proctor (PG) & $\begin{array}{c}0.006^{* * *} \\
(0.002)\end{array}$ & $\begin{array}{c}0.044 \\
(0.073)\end{array}$ & $-3.243^{* * *}$ & $\begin{array}{c}23.762^{* * *} \\
\quad(0.00)\end{array}$ & $\begin{array}{c}1.755 \\
(0.153)\end{array}$ & $\begin{array}{c}-0.037 \\
(0.054)\end{array}$ & $\begin{array}{c}-2.374^{* *} \\
(1.194)\end{array}$ & 0.216 \\
\hline
\end{tabular}


Table 2 (continued)

\begin{tabular}{|c|c|c|c|c|c|c|c|c|}
\hline Equity & $\begin{array}{c}Q \\
(1)\end{array}$ & $\begin{array}{l}\frac{d g}{d S} \\
(2)\end{array}$ & $\begin{array}{c}\text { ADF } \\
(3)\end{array}$ & $\begin{array}{c}\text { Chi-Sq-Test } \\
\{Q ; 0.015\} \\
(4)\end{array}$ & $\begin{array}{c}\text { F-Test } \\
\text { FF-factors } \\
(5)\end{array}$ & $\begin{array}{c}\text { ECM } \\
\pi_{1} \\
(6) \\
\end{array}$ & $\begin{array}{c}\text { ECM } \\
\pi_{2} \\
(7) \\
\end{array}$ & $\begin{array}{c}\text { ECM } \\
R^{2} \\
(8) \\
\end{array}$ \\
\hline AT\&T (SBC) & $\begin{array}{c}0.019^{* * *} \\
(0.002)\end{array}$ & $\begin{array}{c}0.555^{* * *} \\
(0.126)\end{array}$ & $-4.498^{* * *}$ & $\begin{array}{c}7.111^{* * *} \\
(0.008)\end{array}$ & $\begin{array}{c}0.344 \\
(0.794)\end{array}$ & $\begin{array}{c}-0.059 \\
(0.065)\end{array}$ & $\begin{array}{c}-0.097 \\
(0.083)\end{array}$ & 0.075 \\
\hline United Tech (UTX) & $\begin{array}{c}0.014^{* * *} \\
(0.001)\end{array}$ & $\begin{array}{l}0.050 \\
(0.10)\end{array}$ & $-5.278^{* * *}$ & $\begin{array}{c}1.327 \\
(0.249)\end{array}$ & $\begin{array}{c}1.407 \\
(0.239)\end{array}$ & $\begin{array}{c}-0.135 \\
(0.086)\end{array}$ & $\begin{array}{c}-0.07 \\
(0.172)\end{array}$ & 0.060 \\
\hline Verizon (VZ) & $\begin{array}{c}0.017^{* * *} \\
(0.001)\end{array}$ & $\begin{array}{c}0.308^{* * *} \\
(0.094)\end{array}$ & $-5.469 * * *$ & $\begin{array}{l}5.855^{* *} \\
(0.016)\end{array}$ & $\begin{array}{c}2.75^{* *} \\
(0.041)\end{array}$ & $\begin{array}{c}-0.226^{* *} \\
(0.089)\end{array}$ & $\begin{array}{c}-0.02 \\
(0.143)\end{array}$ & 0.077 \\
\hline Walmart (WMT) & $\begin{array}{l}0.004^{* *} \\
(0.002)\end{array}$ & $\begin{array}{l}0.46^{* * *} \\
(0.073)\end{array}$ & $-3.522^{* * *}$ & $\begin{array}{c}37.52^{* * *} \\
(0.00)\end{array}$ & $\begin{array}{c}1.104 \\
(0.346)\end{array}$ & $\begin{array}{c}-0.02 \\
(0.047)\end{array}$ & $\begin{array}{l}-0.059 \\
(0.074)\end{array}$ & -0.049 \\
\hline
\end{tabular}

NOTE: Columns 1 and 2 report estimates (std. errors in parentheses) of the risk aversion parameter, 'Q', and the derivative of the implied Gordon growth rate with respect to sentiment from estimation of equation (2); $\left.\mathbf{P}_{t}=\breve{V}_{t}=\boldsymbol{F Y 1} \mathbf{1}_{t} /\left(\mathbf{1}+\boldsymbol{r}_{t}^{f}+\boldsymbol{Q} \boldsymbol{\beta}_{t} \mathbf{V I X}\right)_{t}\right)^{\boldsymbol{a}}+\mathbf{F Y}_{t} /\left(\mathbf{1}+\boldsymbol{r}_{t}^{f}+\boldsymbol{Q} \boldsymbol{\beta}_{t} \mathbf{V I X} \mathbf{X}_{t}\right)^{\boldsymbol{b}}\left(\overline{\boldsymbol{r}}_{t}^{f}+\right.$ $\left.Q \bar{\beta} \overline{\mathrm{VIX}}-g_{t}\right)$, where, $g_{t}=\alpha_{0}+\alpha_{1}$ RGDP10 $_{t}+\alpha_{2} \mathbf{C P I 1 0}_{t}+\alpha_{3} S_{t}$. Column 3 reports the ADF statistic testing for stationarity of the residuals from equation (2). Column 4 reports results of the test (significance level in parentheses) of the restriction that the equity-specific risk aversion parameter is equal to the mean value of estimates across stocks. Column 5 reports the test statistic (and significance level) for the joint significance of Fama-French and momentum factors. Columns 6 and 7 report estimates of $\boldsymbol{\pi}_{\mathbf{1}}$ and $\boldsymbol{\pi}_{\mathbf{2}}$ from the ECM regression show as equation (3) in the text; $\ln \Delta \boldsymbol{P}_{t}=\boldsymbol{\theta}_{\boldsymbol{i}} \ln \Delta \boldsymbol{P}_{t-1-i}+\phi_{i} \ln \Delta \widehat{\boldsymbol{V}}_{t-i}+\lambda_{i} \ln \Delta \widetilde{\boldsymbol{V}}_{t-i}+\pi_{1} E C M_{1, t-1}+\pi_{2} E C M_{2, t-1}$, where $E C M_{1, t-1}=\ln (P / \widehat{V})_{t-1}$ and $E C M_{2, t-1}=\ln (\widehat{V} / \widetilde{\boldsymbol{V}})_{t-1}$. The $\overline{\boldsymbol{R}}^{2}$ statistic for the ECM regression is shown in the final column. Significant coefficient estimates at 10,5 and 1 percent are indicated by ${ }^{*}, * *$ and ${ }^{* * *}$ respectively. We change these to ${ }^{+,++,++}$if the sign of the coefficient is opposite to what was expected. 